\title{
BDNF-Mediated Cerebellar Granule Cell Development Is Impaired in Mice Null for CaMKK2 or CaMKIV
}

\author{
Manabu Kokubo, ${ }^{1 *}$ Masahiro Nishio, ${ }^{1 *}$ Thomas J. Ribar, ${ }^{1}$ Kristin A. Anderson, ${ }^{1}$ Anne E. West, ${ }^{2}$ and Anthony R. Means ${ }^{1}$ \\ Departments of ${ }^{1}$ Pharmacology and Cancer Biology and ${ }^{2}$ Neurobiology, Duke University Medical Center, Durham, North Carolina 27710
}

\begin{abstract}
The $\mathrm{Ca}^{2+} /$ calmodulin-activated kinases CaMKK2 and CaMKIV are highly expressed in the brain where they play important roles in activating intracellular responses to elevated $\mathrm{Ca}^{2+}$. To address the biological functions of $\mathrm{Ca}^{2+}$ signaling via these kinases during brain development, we have examined cerebellar development in mice null for CaMKK2 or CaMKIV. Here, we demonstrate that CaMKK2/ CaMKIV-dependent phosphorylation of cAMP response element-binding protein (CREB) correlates with $B d n f$ transcription, which is required for normal development of cerebellar granule cell neurons. We show in vivo and in vitro that the absence of either CaMKK2 or CaMKIV disrupts the ability of developing cerebellar granule cells in the external granule cell layer to cease proliferation and begin migration to the internal granule cell layer. Furthermore, loss of CaMKK2 or CaMKIV results in decreased CREB phosphorylation (pCREB), $B d n f$ exon I and IV-containing mRNAs, and brain-derived neurotrophic factor (BDNF) protein in cerebellar granule cell neurons. Reexpression of CaMKK2 or CaMKIV in granule cells that lack CaMKK2 or CaMKIV, respectively, restores pCREB and BDNF to wild-type levels and addition of BDNF rescues granule cell migration in vitro. These results reveal a previously undefined role for a CaMKK2/CaMKIV cascade involved in cerebellar granule cell development and show specifically that $\mathrm{Ca}^{2+}$-dependent regulation of BDNF through CaMKK2/CaMKIV is required for this process.
\end{abstract}

\section{Introduction}

Neuronal cells develop through a sequence of temporal events consisting of proliferation, differentiation, migration, and maturation. In the cerebellum, the most abundant neurons, the cerebellar granule cells (CGCs), are derived from granule cell precursors (GCPs) which migrate from the rhombic lip to form a secondary proliferative zone in the external granule cell layer (EGL) (Altman and Bayer, 1997). During postnatal development, GCPs in the EGL cease proliferation and migrate again to form the internal granule cell layer (IGL), where they make afferent synaptic connections with the Purkinje cells (Altman and Bayer, 1997; Komuro and Yacubova, 2003). Precise regulation of this process requires the actions of brain-derived neurotrophic factor (BDNF) (Lindholm et al., 1997; Schwartz et al., 1997; Huang and Reichardt, 2001). BDNF influences CGC development by promoting GCP exit from the cell cycle, acting as a chemokinetic factor to induce GCP migration, and functioning as a chemotactic factor to ensure that the migrating GCPs are moving in the correct orientation (Borghesani et al., 2002; Choi et al., 2005; Zhou et al., 2007).

$\mathrm{BDNF}$ expression is tightly regulated by $\mathrm{Ca}^{2+}$-mediated sig-

\footnotetext{
Received Jan. 5, 2009; revised June 1, 2009; accepted June 8, 2009.

This work was supported by National Institutes of Health Grant DK74701-35 (A.R.M.) and the National Alliance for Research on Schizophrenia and Depression Young Investigator Award (A.E.W.). We thank Rob Wechsler-Reya and Audra Lee for helpful discussions regarding the design and implementation of experiments involving cerebellar granule cells.

${ }^{*}$ M.K. and M.N. contributed equally to this work.

Correspondence should be addressed to Dr. Anthony R. Means, Department of Pharmacology and Cancer Biology, Duke University Medical Center, P.0. Box 3813, Durham, NC 27710. E-mail: means001@mc.duke.edu.

M. Kokubo's present address: Nagoya University, Nagoya 464-8601, Japan.

M. Nishio's present address: Mie University, Tsu City 514-8507, Japan.

D0I:10.1523/JNEUROSCI.0040-09.2009

Copyright $\odot 2009$ Society for Neuroscience $\quad$ 0270-6474/09/298901-13\$15.00/0
}

naling pathways which are crucial modulators of $B d n f$ transcription (West et al., 2001). $\mathrm{Ca}^{2+}$ signaling drives Bdnf transcription in part through the transcription factor cAMP response elementbinding protein (CREB), which becomes phosphorylated at Ser ${ }^{133}$ (Tabuchi et al., 2002; Greer and Greenberg, 2008; Hong et al., 2008). In neurons, CREB Ser ${ }^{133}$ phosphorylation can be induced by multiple kinases, including $\mathrm{Ca}^{2+}$-calmodulin dependent protein kinase IV (CaMKIV) (Finkbeiner, 2000; Mayr and Montminy, 2001). However, which kinases are required for CREB-dependent transcription of $B d n f$ under physiological conditions has remained unknown. In addition, given that $B d n f$ can also be transcribed by activity- and CREB-independent mechanisms (Hong et al., 2008), to what extent $\mathrm{Ca}^{2+}$ and/or CREBdependent $B d n f$ transcription are required for proper BDNF expression during early development is not known.

In vivo, CaMKIV modulates both basal and rapid activitydependent phosphorylation of CREB at $\operatorname{Ser}^{133}$ in neurons (Ho et al., 2000; Ribar et al., 2000). CaMKIV, which was identified in CGCs (Ohmstede et al., 1989), must be phosphorylated by an upstream CaMKK to generate the autonomous activity required for nuclear entry and CREB phosphorylation (Chow et al., 2005). Of the two identified mammalian CaMKKs (Wayman et al., 2008), CaMKK2 is also expressed in CGCs (Vinet et al., 2003; Sato et al., 2006). To determine whether the CaMKK2/CaMKIV signaling cascade is required for cerebellar development, we have used mice null for either Camkk2 or Camk4. We find that loss of CaMKK2 or CaMKIV impairs the ability of GCPs to cease proliferation in the EGL and migrate to the IGL, and provide evidence that this migration failure may be due to reduced CREB phosphorylation and reduced BDNF expression in GCPs. Reexpression of CaMKIV or CaMKK2 in null cells results in full restoration of 
CREB phosphorylation and BDNF expression. Thus, the $\mathrm{Ca}^{2+}$ / CaM/CaMKK2/CaMKIV/CREB signaling cascade is required for regulation of the production of BDNF in the postnatal cerebellum and for execution of the program that mediates CGC development.

\section{Materials and Methods}

Animals. Camk4 ${ }^{-1-}$ mice were generated in our laboratory as previously described (Wu et al., 2000) and backcrossed into a C57BL/6J background for $>20$ generations. Camkk2 ${ }^{-1-}$ mice were also generated in our laboratory as previously described (Anderson et al., 2008) and were backcrossed into the C57BL/6J background for three generations. Control mice for both null lines were generated from F1 heterozygous matings and backcrossed to C57BL/6J backgrounds for 20 and 3 generations, respectively. All animals were bred and maintained in the Duke University Levine Science Research Building animal facilities under a $12 \mathrm{~h}$ light (6 A.M.- 6 P.M.), $12 \mathrm{~h}$ dark cycle (6 P.M.- 6 A.M.). Food and water were provided ad libitum and all care was given in compliance within National Institutes of Health and Duke University institutional guidelines on the care and use of laboratory and experimental animals under an Institutional Animal Care and Use Committee approved protocol.

Immunoblotting. Immunoblots were performed essentially as previously described (Ribar et al., 2000). Samples were fractionated by SDS-PAGE and transferred to Immobilon-P membranes (Millipore). Membranes were blocked in TBS containing 5\% nonfat milk. Primary and secondary antibody incubations were in TBS containing 5\% nonfat milk, $0.01 \%$ Tween 20 , and $0.01 \%$ fish-gelatin oil (Sigma). Washes were in TBS with $0.5 \%$ Tween 20. Anti-CaMKIV (BD Biosciences) was used at 1:2000, anti CaMKK $\beta$ (Santa Cruz Biotechnology) at 1:200, anti-CREB/ anti-CREB phosphorylation (pCREB) (Upstate Biotechnology) at 1:1000, and anti-BDNF (Santa Cruz Biotechnology) at 1:100. Secondary antibodies conjugated with Alexafluor 680 (Invitrogen) or IR800 (Rockland Immunochemicals) were used at 1:5000. Membranes were visualized using an Odyssey infrared scanner (LI-COR) and quantified using the Odyssey software version 2.1 according to the manufacturer's instructions.

Histology and immunostaining. Histology and immunostaining was performed as described previously (Ribar et al., 2000). Briefly, for adults, whole brains were dissected out, formalin-fixed, embedded in paraffin, and $10 \mu \mathrm{m}$ midsagittal sections were cut on a rotary microtome. Due to size and orientation issues when embedding in paraffin, postnatal day 7 mice (P7) were anesthetized and perfused with $4 \%$ paraformaldehyde. Whole cerebella were dissected out, frozen in isopentane and $15 \mu \mathrm{m}$ midsagittal cryostat sections were prepared. Morphology was visualized by staining with $0.05 \%$ cresyl violet. Planimetric measurements used to calculate the total cross-sectional area of the cerebellum, as well as the IGL and EGL were performed on nonadjacent midsagittal sections by tracing the outline of these regions on a digital picture that was captured using an Axio Imager upright microscope and AxioVision software version 4.6 (Carl Zeiss). Once the region of interest (ROI) was defined for each midsagittal section, the area inside the ROI was quantified using the Axiovision software. Planimetric EGL width was measured at the midpoint of the fifth and ninth folia by methods previously described (Schwartz et al., 1997). Manual IGL and EGL cell counts were performed on digital images captured at $20 \times$ magnification. A $1 \mathrm{~mm}^{2}$ box was positioned at the midpoint of the fifth and ninth folia and cells were counted and averaged. In all the procedures described above, measurements were performed in five nonadjacent mid-sagittal sections per individual mouse. Five sets of WT, Camk4 ${ }^{-1-}$, and Camkk2 ${ }^{-1-}$ mice were used. For immunostaining, sections were permeabilized for $10 \mathrm{~min}$ in $0.05 \%$ Triton X, $20 \mathrm{~mm}$ Tris pH 7.4, $50 \mathrm{~mm} \mathrm{NaCl}, 300 \mathrm{~mm}$ sucrose, and 3 $\mathrm{mM} \mathrm{MgCl}_{2}$. After permeabilization, the sections were washed and blocked for $20 \mathrm{~min}$ in 5\% normal goat serum/PBS and then incubated overnight at $4^{\circ} \mathrm{C}$ with anti-KI67 (BD Biosciences) at 1:100 or anticalbindin D28k (Sigma) at 1:1000. The sections were washed and incubated in the dark for $1 \mathrm{~h}$ with either anti-rabbit-cy3 for KI-67 or anti-mouse-cy3 for calbindin D28k (Jackson ImmunoResearch) diluted 1:200 in 5\% goat serum/PBS, washed again, and mounted in Vectashield hard-set mounting media with DAPI (Vector Laboratories). All washing steps were $3 \times 5 \mathrm{~min}$ with $\mathrm{PBS}$ at room temperature, except for the $4^{\circ} \mathrm{C}$ incubation with primary antibody. Immunostaining of isolated GCPs was done using the same procedure outlined above after the cells were fixed for $10 \mathrm{~min}$ in $1 \%$ paraformaldehyde/PBS. The count nuclei module in the MetaMorph 7 Image Analysis software (Molecular Devices) was used to determine the average intensity of immunofluorescence for KI-67 per cell in the EGL. Approximately 100-200 cells were assayed in five nonadjacent mid-sagittal sections per individual mouse. Four sets of WT, Camk4 ${ }^{-1-}$, and Camkk2 $2^{-1-}$ mice were used.

In vivo BrdU labeling and TUNEL assay. P7 mice were injected subcutaneously with $50 \mathrm{mg} / \mathrm{kg}$ 5-bromo-2' -deoxyuridine (Sigma) and the animals were killed at either 24 or $48 \mathrm{~h}$ after injection. Whole brains were isolated as described in the histology section. Brain sections were then fixed and permeabilized as described above, treated for $1 \mathrm{~h}$ at $37^{\circ} \mathrm{C}$ with 1 $\mathrm{N} \mathrm{HCl}$ followed by two $10 \mathrm{~min}$ washes in $0.1 \mathrm{M}$ sodium borate and immunostained as described with anti-BrdU (Roche) at 1:50, and visualized with anti-mouse FITC secondary antibodies (Jackson ImmunoResearch). In migration experiments the number of labeled cells per square millimeter in each defined layer was counted in five nonadjacent mid-sagittal sections at the midpoint of the fifth and ninth folia. Four sets of WT, Camk4 $4^{-1-}$, and Camkk2 $2^{-1-}$ mice were used.

Saggital brain sections from P7 mice were also used for the TUNEL assay, which used a commercially available kit (ApopTag Kit, Millipore Bioscience Research Reagents) following the manufacturer's instructions. Briefly, sections were postfixed with ethanol:acetic acid (2:1) for 5 $\mathrm{min}$, and endogenous peroxidase quenched with $3 \% \mathrm{H}_{2} \mathrm{O}_{2}$ for $5 \mathrm{~min}$. The sections were incubated with a TdT enzyme and a mixture of digoxigenin-labeled nucleotides for $60 \mathrm{~min}$. This was followed by incubation with anti-digoxigenin-peroxidase for $30 \mathrm{~min}$, and color development with $\mathrm{H}_{2} \mathrm{O}_{2}$-diaminobenzidine for 3-6 min. TUNEL-positive cells in the EGL were counted in five nonadjacent sections as previously described and the number of TUNEL-positive cells per square millimeter was calculated for each animal. Four sets of mice representing either WT, Camk4 ${ }^{-1-}$, and Camkk2 ${ }^{-1-}$ were used.

BDNF ELISA assay. BDNF protein levels were determined from P7 GCPs using the BDNF Emax Immunoassay Kit (Promega), following the manufacture's instructions. Ninety-six-well immunoplates were coated with $50 \mu \mathrm{l} /$ well monoclonal anti-mouse-BDNF antibody and incubated overnight at $4^{\circ} \mathrm{C}$. Then the plates were washed three times with wash buffer and the samples were incubated in the coated wells (100 $\mu$ l each) for $2 \mathrm{~h}$ at room temperature with shaking. After additional washes, the antigen was incubated with an anti-human BDNF antibody for $2 \mathrm{~h}$ at room temperature with shaking. The plates were washed again with wash buffer and then incubated with an anti-IgY HRP for $1 \mathrm{~h}$ at room temperature. After another wash, the plates were incubated with a TMB/peroxidase substrate solution for $15 \mathrm{~min}$ and phosphoric acid $1 \mathrm{M}(100 \mu \mathrm{l} /$ well $)$ was added to the wells. The colorimetric reaction product was measured at $450 \mathrm{~nm}$ using a microplate reader. BDNF concentrations were determined from the regression line for the BDNF standard (ranging from 7.8 to $500 \mathrm{pg} / \mathrm{ml}$-purified mouse BDNF) incubated under similar conditions in each assay.

RNA isolation real-time-PCR. Total RNA from P7 freshly isolated GCPs was extracted using RNeasy Mini Kit (Qiagen) and quantified spectrophotometrically. DNase treatment of total RNA was performed by using a Turbo DNA-Free Kit (Ambion) according to the manufacturer's instructions. Single-stranded cDNA was synthesized using SuperScript II RNase H Reverse Transcriptase (Invitrogen) according to the manufacturer's directions. All samples were subjected to 40 cycles of real-time PCR using PowerSYBR green detection on an ABI 7300 and the following primers: $B d n f$ exon 9 (coding), 5'-GATGCCGCAAACATGTCTATGA-3' (forward) and 5'-TAATACTGTCACACACG CTCAGCTC-3' (reverse), Bdnf exon 1, 5'-AGTCTCCAGGACAGCAAAGC-3' (forward), 5'-GCCTTCATGCAACCGAAGTA-3' (reverse), Bdnf exon IV, 5'-CCCTCCCCCTTTTAACTGAA-3' (forward), 5' GCCTTCATGCAACCGAAGTA-3' (reverse), Gapdh, 5' -CATGGCCTTCCGTGTTCTCCT-3' (forward), 5' -TGATGTT GATGTCATCATACTTGGCAGGTT-3' (reverse). Primer efficiency was tested within each experiment, and product quantities were calculated from a standard 
curve. Transcript levels were normalized for RNA from Gapdh as a control for sample preparation and handling. To combine data from multiple independent experiments, normalized values of $B d n f$ mRNA were scaled to the average WT level in each experiment.

Cerebellar micro-explants. Micro-explant cultures were prepared from freshly isolated cerebella of P3 mice from all three genotypes as previously described (Nagata and Nakatsuji, 1990). Briefly, cerebella were aseptically dissected out and manually sliced into small tissue pieces which measured $\sim 7 \mu \mathrm{m} \times 7 \mu \mathrm{m} \times 7 \mu \mathrm{m}$ or $\sim 300 \mu \mathrm{m}^{3}$. The sliced cerebellar pieces were then manually transferred to precoated $(100 \mu \mathrm{g} / \mathrm{ml}$ poly-D-lysine and $20 \mu \mathrm{g} / \mathrm{ml}$ laminin) coverslips and placed in tissue culture dishes containing Basal Medium Eagle's with Earle's salts (BME, Invitrogen) supplemented with $1 \mathrm{mg} / \mathrm{ml} \mathrm{BSA} ; 10 \mu \mathrm{g} / \mathrm{ml}$ insulin; $35 \mathrm{~nm}$ selenate; $5.5 \mu \mathrm{g} / \mathrm{ml}$ transferin; $0.1 \mathrm{~nm} \mathrm{T4} ; 0.25 \%$ glucose; $1 \mu \mathrm{g} / \mathrm{ml}$ aprotinin; $2 \mathrm{~mm}$ glutamine and penicillin/streptomycin. Cerebellar pieces were then incubated in a $95 \% \mathrm{O}_{2} / 5 \% \mathrm{CO}_{2}$ atmosphere at $37^{\circ} \mathrm{C}$ for $7 \mathrm{~d}$ before mounting the coverslips on glass slides for analysis. Conditioned media used in some experiments was prepared by removing the culture media of micro-explants which had been cultured for $>7$ but $<14 \mathrm{~d}$. Fresh micro-explants were then prepared and immediately plated with conditioned media. After $48 \mathrm{~h}$ in culture, more freshly conditioned media was added. For some micro-explant experiments, media was supplemented with either $100 \mathrm{ng} / \mathrm{ml}$ recombinant BDNF (Sigma) or $1 \mu \mathrm{g} / \mathrm{ml}$ recombinant TrkB-Fc (R\&D Systems).

Primary granule cell isolation. GCPs were purified using a modification of the procedures previously described (Wechsler-Reya and Scott, 1999). Briefly, cerebella from P7 mice were removed aseptically, cut into small pieces, and incubated at $37^{\circ} \mathrm{C}$ for $30 \mathrm{~min}$ in digestion buffer consisting of Dulbecco's PBS (DPBS, Invitrogen) with $10 \mathrm{U} / \mathrm{ml}$ papain (Worthington), $200 \mu \mathrm{g} / \mathrm{ml} \mathrm{L}$-cysteine, and $250 \mathrm{U} / \mathrm{ml}$ DNase (Sigma). The digestion buffer was then removed and replaced with DPBS containing $8 \mathrm{mg} / \mathrm{ml}$ soybean trypsin inhibitor, $8 \mathrm{mg} / \mathrm{ml}$ bovine serum albumin (BSA), and $250 \mathrm{U} / \mathrm{ml}$ DNase, and tissue was triturated using pipettes of decreasing bore size to obtain a single-cell suspension. Cells were centrifuged at room temperature and resuspended in PBS containing $200 \mu \mathrm{g} / \mathrm{ml} \mathrm{BSA}$ (PBS/BSA). The cell suspension was passed through a cell strainer (Becton Dickinson) to remove debris and then recentrifuged and resuspended in fresh PBS/BSA. The cell suspension was underlayed with a step gradient of 35\% and 65\% Percoll (Sigma) and centrifuged at $2500 \mathrm{rpm}$ for $12 \mathrm{~min}$ at room temperature. GCPs were harvested from the $35 / 65 \%$ interface, washed in PBS/BSA, resuspended in Dulbecco's Modified Eagle's Medium (DMEM, Invitrogen) containing 20\% equine serum and supplemented with sodium pyruvate ( $1 \mathrm{~mm})$, L-glutamine $(2 \mathrm{~mm})$, and penicillin/streptomycin. Cells were then transferred to tissue culture dishes coated with $100 \mu \mathrm{g} / \mathrm{ml}$ poly-D-lysine and incubated in a $95 \% \mathrm{O}_{2} / 5 \% \mathrm{CO}_{2}$ atmosphere at $37^{\circ} \mathrm{C}$ for a minimum of $24 \mathrm{~h}$ and a maximum of $72 \mathrm{~h}$.

Lentiviral construct expression. cDNA's for CaMKIV-WT and CaMKK2-WT (active) or CaMKIV-K71M and CaMKK2-K193E (inactive) were cloned and all constructs were verified by DNA sequencing (Duke University Core Sequencing Facility). Lentivirus was generated as described previously (Rubinson et al., 2003) using HEK 293T cells which were cultured according to the suppliers instructions (ATCC). Viral titers were determined by infection of HEK 293T cells and then determining the total number of cells expressing the GFP marker along with immunoblotting of cell extracts to determine the amount of expressed protein that best reflected wild-type levels. Add-back experiments were performed as follows: GCPs from P7 mice were isolated as described, plated at high density $\left(2-4 \times 10^{6}\right.$ cells/well $)$ in DMEM on a poly-D-lysine coated 6-well tissue culture plate. After allowing the cells to settle, lentiviral constructs containing either the active kinase, inactive kinase or empty vector were added to the plate. Cells were incubated $\sim 16 \mathrm{~h}$ in a $95 \% \mathrm{O}_{2} / 5 \% \mathrm{CO}_{2}$ atmosphere at $37^{\circ} \mathrm{C}$. The media was then removed from the plate and cells were rinsed three times with fresh DMEM, then incubated for $3 \mathrm{~d}$ after infection in a $95 \% \mathrm{O}_{2} / 5 \% \mathrm{CO}_{2}$ atmosphere at $37^{\circ} \mathrm{C}$ to allow for maximal expression. Cells were then harvested and subjected to immunoblot analysis as previously described. Infection efficiency of GCPs with lentivirus was $90 \%$ on average as determined by the percentage of GFP-positive cells.
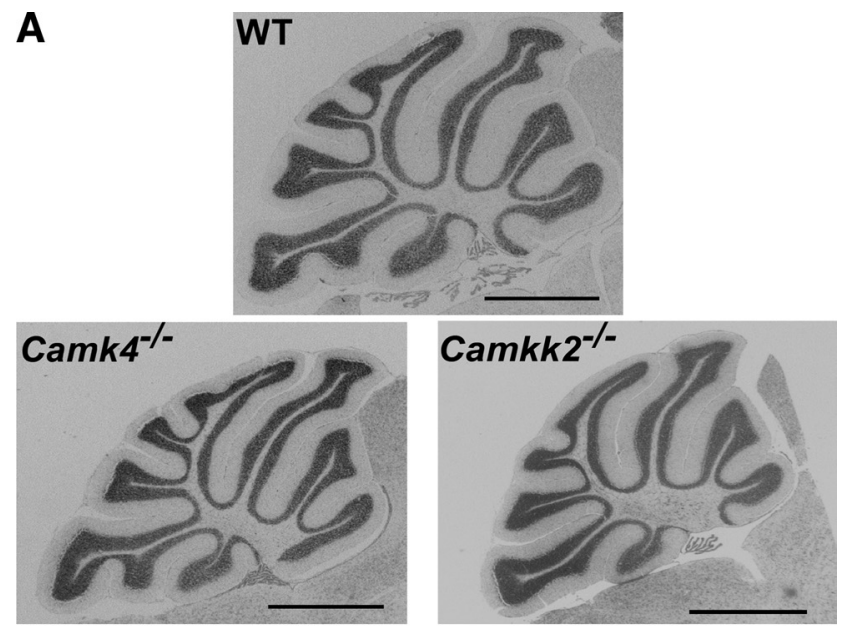

B

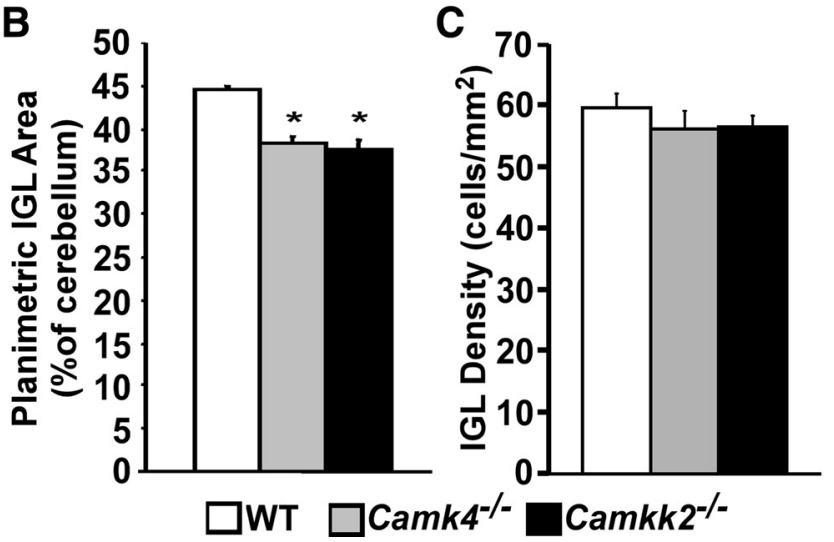

Figure 1. Planimetric analysis of the cerebellum from adult WT, Camk $4^{-1-}$, and Camkk2 ${ }^{-1-}$ mice. A, Mid-sagittal cerebellar sections from 3-month-old WT, Camk4 ${ }^{-1-}$, and Camkk2 ${ }^{-1-}$ mice were stained with cresyl violet and photographed at $1 \times$ magnification. Shown are representative cerebellar sections (scale bars, $1 \mathrm{~mm}$ ). $\boldsymbol{B}$, The percentage of the IGL cross-sectional area compared with the whole cerebellum was quantified as described in Materials and Methods. The percentage of the cerebellar cross-sectional area relegated to the IGL was decreased from $44.3 \%$ in the wild-type to $38.4 \%$ in the Camk $4^{-1-}$ and $37.5 \%$ in the Camkk $2^{-1-}$ mice. Values shown are mean \pm SEM $\left({ }^{*} p<0.01\right.$ for difference against WT; $n=$ 5 for each genotype). C, Three-month-old Camk4 ${ }^{-1-}$ and Camkk2 ${ }^{-1-}$ mice show no difference in IGL cell density compared with WT (values shown are mean $\pm \mathrm{SEM} ; n=5$ for each genotype).

Statistical analysis. Statistical comparisons were performed using the Graphpad Prizim software version 4.0.3 (Graphpad Software). All data were subjected to a one-way ANOVA and post hoc analysis was completed using the paired student-Newman-Keuls test. Graph data are presented as the mean, and the error bars represent the SEM. Differences were considered significant when $p<0.05$.

\section{Results}

Structural analysis of Camk4 $4^{-/-}$and Camkk2 $2^{-1-}$ cerebella We have previously shown that adult Camk $4^{-1-}$ mice exhibit both morphological and physiological deficits in Purkinje cells (Ribar et al., 2000). While we have not done any comprehensive measurements of any physiological parameters in the Purkinje cells from Camkk2 $2^{-/-}$mice, we do find a remarkable similarity in the overall morphology of these cells compared with the Camk $4^{-1-}$ mice (supplemental Fig. 1, available at www.jneurosci.org as supplemental material). However, while CaMKIV is transiently expressed in Purkinje cells during development, it is most highly expressed in CGCs starting early in development and continues to be expressed in these cells through adulthood (Jensen et al., 1991). Additionally, CaMKK2 which is an upstream activator 
of CaMKIV is also expressed in both the Purkinje and granule cells of the cerebellum in a similar pattern (Vinet et al., 2003; Sato et al., 2006). Thus, to investigate the role of these CaMKs in the cerebellum, particularly CGCs, we used lines of Camk4 ${ }^{-1-}$ and Camkk2 $2^{-1-}$ mice generated in our laboratory (Wu et al., 2000, Anderson et al., 2008).

We previously established that in the cerebellum, Camk4 $4^{-1-}$ mice do not show compensatory changes in other CaMKs or kinases such as PKA that phosphorylate substrates in common with CaMKIV (Ribar et al., 2000). The Camkk2 $2^{-1-}$ mice also failed to show compensatory changes in the other CaMKs or kinases such as PKA (data not shown). As previously reported, there also were no significant differences in folia or laminar organization of the adult cerebellum between wild-type (WT) and Camk4 ${ }^{-1-}$ mice (Ribar et al., 2000). Similarly, Camkk2 ${ }^{-/-}$mice did not show significant foliation or laminar deficits in the cerebellum (Fig. 1A). Since both CaMKIV and CaMKK2 are highly expressed in postpubertal CGCs, we initiated a more comprehensive analysis of the granule cell layer in these mice. The size and weight of the cerebellum was not significantly different between Camk4 ${ }^{-I-}$, Camkk2 ${ }^{-1-}$, or WT mice and the morphology of the granule cells did not appear to be altered in either of the null mice compared with WT. Quantitative planimetric analysis of the cerebellum in adult mice revealed that in midsagittal sections, the cross-sectional area of the IGL in both Camk4 ${ }^{-1-}$ and Camkk2 $2^{-1-}$ mice was significantly reduced compared with WT (Fig. $1 B$ ). However, there was no significant difference in cell density between WT, Camk4 $4^{-1-}$, or Camkk2 ${ }^{-1-}$ mice in the IGL (Fig. 1C). These data suggested that the adult IGL was smaller due to less CGCs being present and prompted us to evaluate changes in the CGCs during early cerebellar development.

Cerebellar development is a dynamic process in which GCPs proliferate in the outer part of the EGL, become postmitotically differentiated in the inner-part of the EGL, migrate inward through the molecular layer (ML) to form the IGL, and refine synaptic connections with the Purkinje cells in the IGL (Altman and Bayer, 1997; Komuro and Yacubova, 2003). Since the peak of this proliferation process occurs around P7 (Altman and Bayer, 1997), we examined cerebella from Camk4 $4^{-1-}$ and Camkk2 $2^{-1-}$ mice at this age. At P7, the morphology of the cerebellum was similar in both folia development and laminar organization between WT, Camk4 ${ }^{-1-}$ and Camkk2 $2^{-1-}$ mice (Fig. 2 A, B). However quantitative planimetric analysis of the cerebellum in P7 mice revealed that in midsagittal sections, the cross-sectional area of the EGL in both Camk $4^{-1-}$ and Camkk2 $2^{-1-}$ mice was significantly increased compared with WT mice (Fig. 2C). Measure-
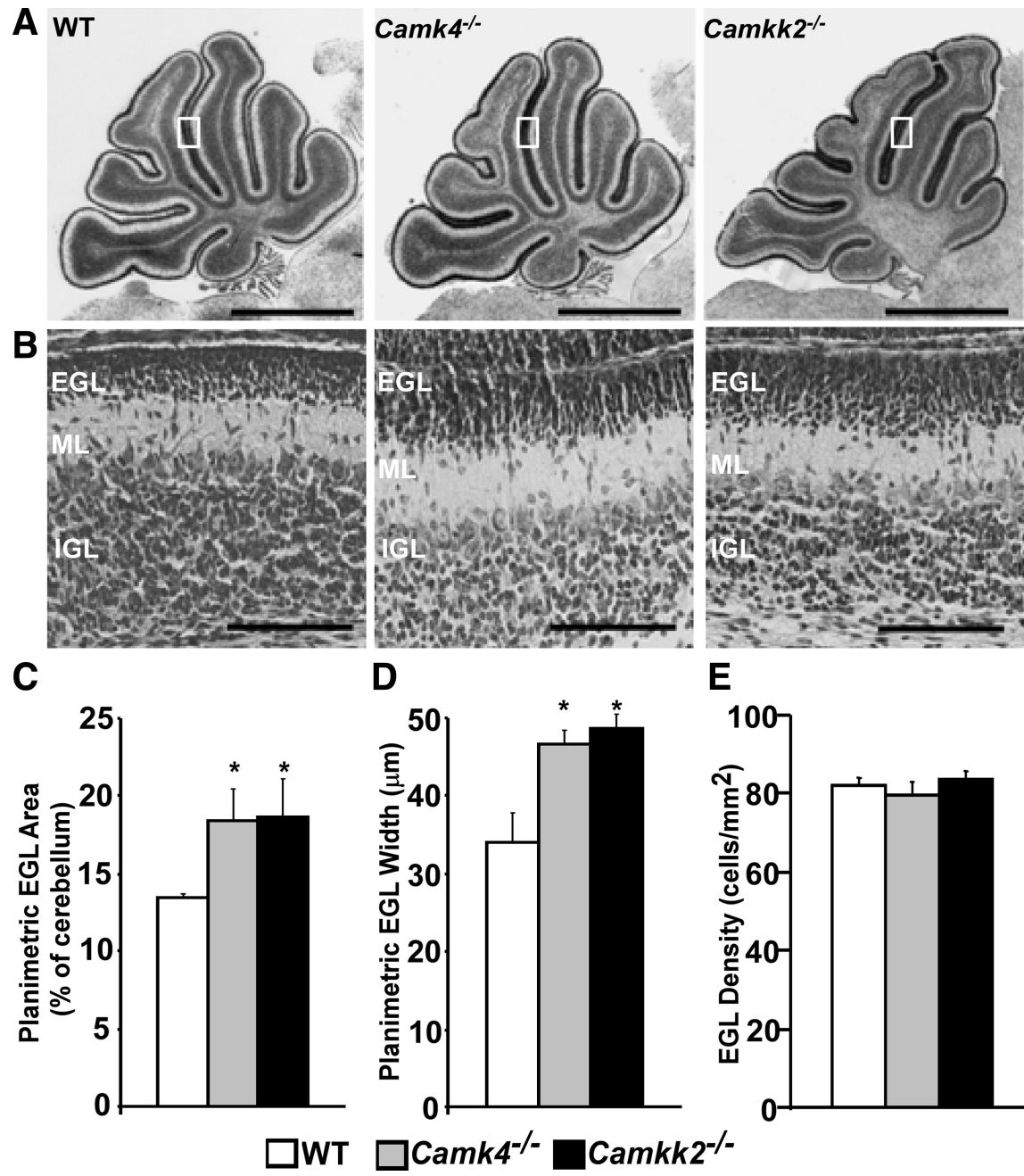

D

$\mathrm{E}$
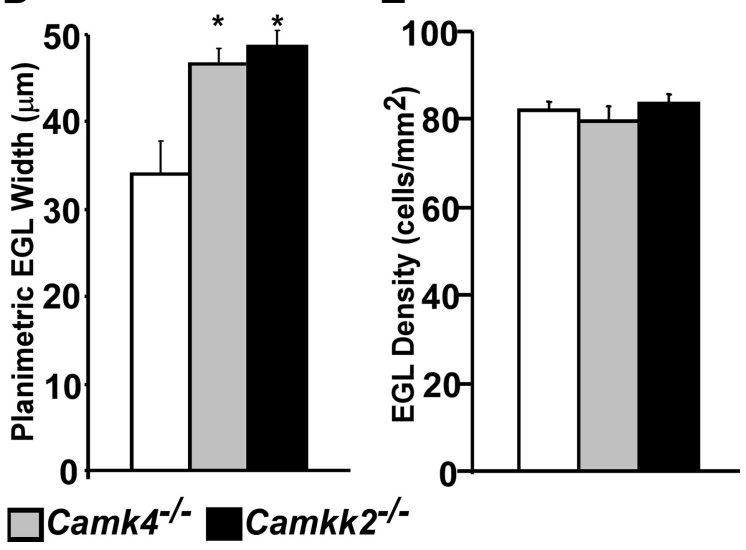

Figure 2. Structural analysis of the cerebellum from postnatal 7-d-old WT, Camk4 ${ }^{-1-}$, and Camkk2 ${ }^{-1-}$ mice. $A$, Mid-sagittal sections from P7 WT, Camk4 ${ }^{-1-}$, and Camkk2 ${ }^{-1-}$ mice were stained with cresyl violet and photographed at $1 \times$ magnification. Shown are representative cerebellar sections (scale bars, $1 \mathrm{~mm}$ ). $\boldsymbol{B}$, Representative sections of cerebella derived from P7 WT, whole cerebellum was quantified as described in Materials and Methods. The percentage of the cerebellar cross-sectiona 列 the EGL width shows a significant increase in the Camk4 $4^{-1-}$ and Camkk2 $2^{-1-}$ mice compared with WT. Values shown are mean \pm SEM $\left({ }^{*} p<0.05\right.$ for difference against WT; $n=5$ for each genotype). $\boldsymbol{E}$, Seven-day-old Camk4 ${ }^{-1-}$ and (amkk2 ${ }^{-1-}$ mice show no difference in EGL cell density compared with WT (values shown are mean $\pm S E M ; n=5$ for each genotype).

ment of the cross-sectional width of the EGL also revealed a significant increase in both null mice (Fig. $2 D$ ), but there was no difference in cell density (Fig. $2 E$ ). These results indicate that in the null mice, the expansion in EGL size is attributable primarily to an increase in the total number of GCPs residing in the developing EGL of both Camk4 $4^{-1-}$ and Camkk2 $2^{-1-}$ mice relative to WT mice.

Increased proliferation and increased apoptosis in the EGL of $\mathrm{Camk4}^{-1-}$ and Camkk2 ${ }^{-1-}$ mice

To analyze whether this increase in cell number was caused by hyper-proliferation of GCPs in the EGL of $C a m k 4^{-1-}$ and Camkk2 $2^{-1-}$ mice, cryostat sections were prepared from postnatal day 7 mice and immunostained with KI-67, a general marker of cells in the proliferative cycle. In WT mice, proliferating cells immunostained with KI-67 were present throughout the EGL 

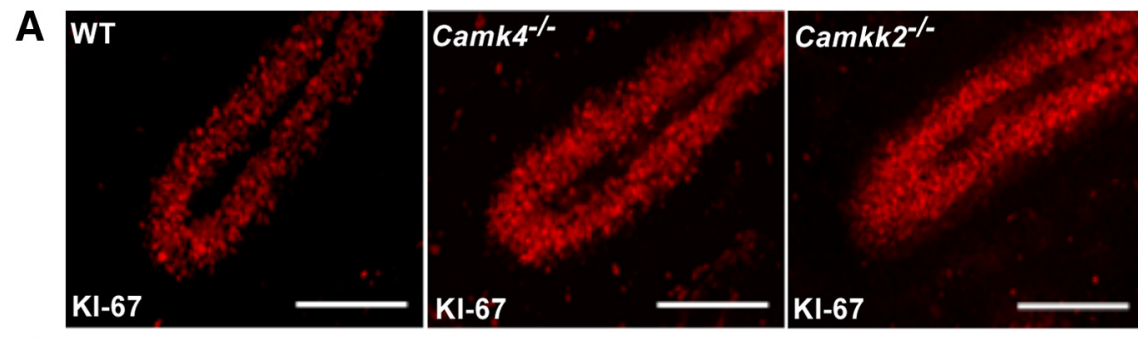

B
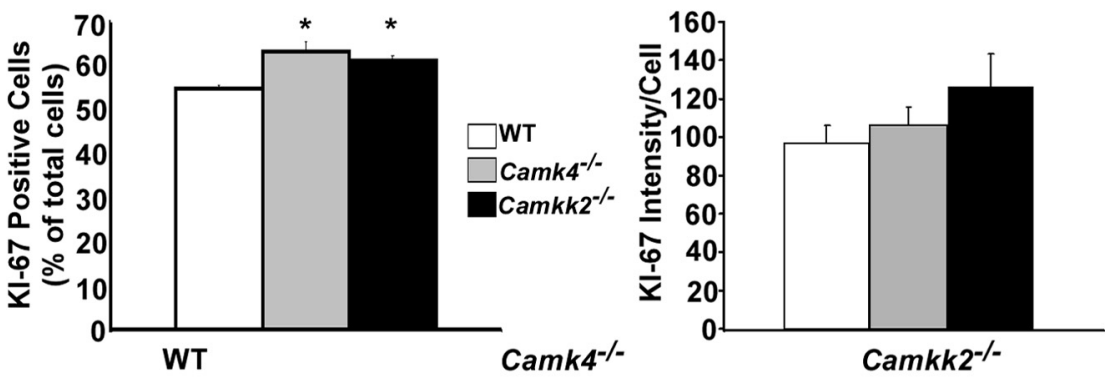

\section{C}
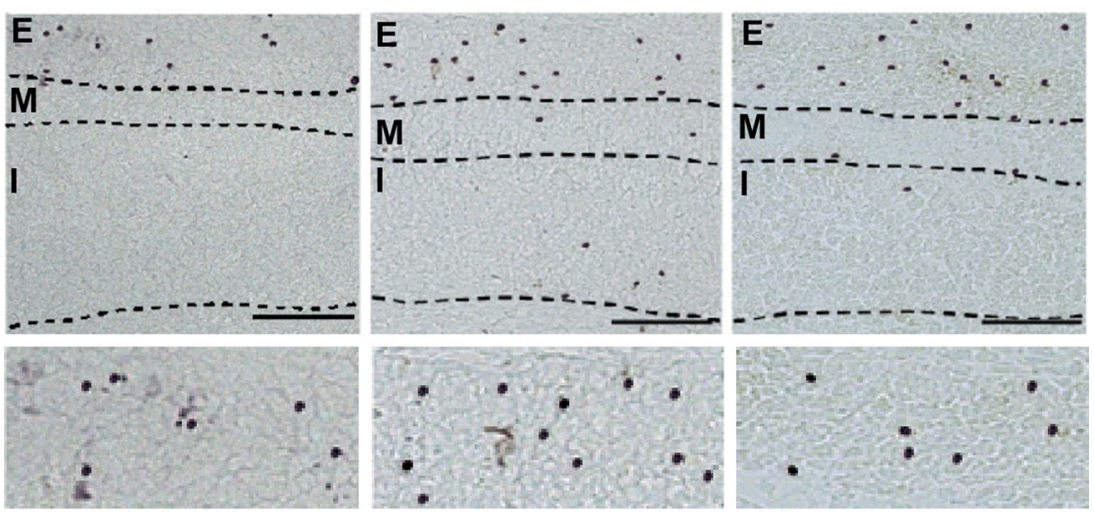

D

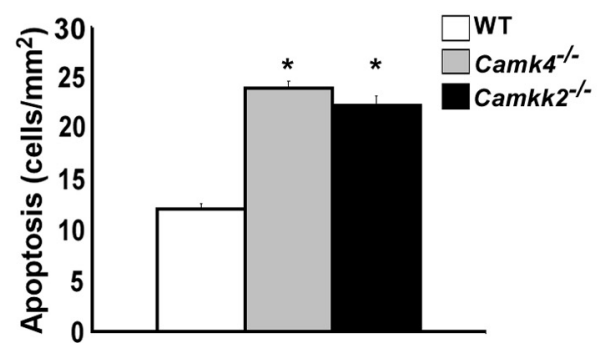

Figure 3. Camk4 $4^{-1-}$ and Camkk2 $2^{-1-}$ mice have increased cell proliferation and apoptosis in the EGL at postnatal day 7.A Representative photograph showing the identification of proliferating cells after immunolabeling against the Ki- 67 nuclear antigen. Note the relative increase in cells staining positive in the sections from both the Camk4 ${ }^{-1-}$ and Camkk2 ${ }^{-1-}$ mice (scale bars, $100 \mu \mathrm{m}) . \boldsymbol{B}$, The left panel shows the quantification of the total percentage of Ki-67-positive cells in the EGL area. The right panel shows that there was no difference in the average staining intensity of the cells, thus confirming the increase in proliferating cells from both null mice. Values shown are mean \pm SEM $\left({ }^{*} p<0.05\right.$ for difference against WT; $p=0.3$ for difference in staining intensity; $n=4$ for each genotype). $C$, The top is a representative photograph of apoptotic GCPs in wild-type, Camk4 ${ }^{-1-}$, and Camkk2 $2^{-1-}$ mice identified by Tunnel staining (scale bars, $50 \mu \mathrm{m}$ ). The bottom is a higher magnification to demonstrate that the nuclei are indeed positively stained. $\boldsymbol{D}$, Quantification showing an increase in the number of TUNEL-positive cells per square millimeter in the EGL of Camk4 ${ }^{-/-}$and Camkk2 ${ }^{-/-}$mice compared with WT. Values shown are mean \pm SEM $\left({ }^{*} p<0.01\right.$ for difference against WT; $n=4$ for each genotype).

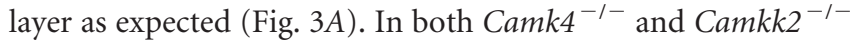
mice, however, there is an increase in $\mathrm{Ki}-67$ staining intensity throughout the EGL suggesting an increase in the number of proliferating cells (Fig. 3A). Indeed, quantification of the KI-67positive cells within the EGL supported this observation by revealing a small but statistically significant increase in proliferating cells in both the Camk4 ${ }^{-1-}$ and Camkk2 ${ }^{-1-}$ mice compared with WT (Fig. 3B). We also found that there was no difference in average staining intensity (Fig. $3 B$ ) between the genotypes, thus demonstrating that the threshold for staining was equivalent, and confirming that there were indeed more cells which were KI-67-positive (proliferating) in both the Camk4 $4^{-1-}$ and Camkk2 ${ }^{-1-}$ mice.

A reduction of the IGL area in postpubertal null mice coupled with increased GCP proliferation in the developing EGL suggested the possibility that granule cell survival is impaired in both lines of null mice. To test this idea, sagittal cryostat sections of P7 cerebella from WT, $\mathrm{Camk4}^{-1-}$, and Camkk2 ${ }^{-1-}$ mice were examined by TUNEL staining. While a few apoptotic granule cells can be seen in the ML and IGL, the majority of the cells undergoing cell death are mainly localized in the EGL (Fig. 3C). Compared with WT mice, we found that Camk $4^{-1-}$ mice had on average a twofold increase and Camkk2 ${ }^{-1-}$ had a 1.8-fold increase in the number of TUNEL-positive cells in the EGL (Fig. 3D). Of note, this is a similar magnitude of change in apoptosis to that observed in $B d n f^{-l-}$ mice compared with their WT sibs (Schwartz et al., 1997). Together, these results demonstrate that Camk4 ${ }^{-1-}$ and Camkk2 $^{-1-}$ mice had marked developmental similarities with respect to increased proliferation and apoptosis of GCPs in the EGL.

\section{Decreased GCP migration in $\mathrm{Camk}^{-/-}$ and Camkk2 ${ }^{-/-}$mice}

In the developing cerebellum, GCP proliferation and apoptosis is balanced so as to provide the proper number of CGCs. Previous research has shown that in the absence of proper migration, GCPs accumulate in the EGL and results in increased proliferation and apoptosis (Schwartz et al., 1997; Borghesani et al., 2002; Choi et al., 2005). To test whether the increased proliferation and increased apoptosis in both the $\mathrm{Camk4}^{-1-}$ and Camkk2 ${ }^{-1-}$ mice could be attributable to delayed migration, we labeled in vivo a cohort of GCPs born on P7 with a pulse of BrdU and followed the migration of these cells over the next 2 d. As shown in Figure $4 \mathrm{~A}$, most BrdU-labeled GCPs remained in the EGL at $24 \mathrm{~h}$ after labeling. By $48 \mathrm{~h}$, these BrdU-labeled granule cells had begun to migrate and moved to the ML and IGL in mice from each genotype. Quantitatively, there was a significant decrease in the number of BrdU-labeled GCPs from both null mice that had migrated out of the EGL. Concomitant with this retention in the EGL, there was a significant reduction in the number of BrdU-labeled cells detected in the molecular layer and the IGL of both Camk4 $4^{-1-}$ and Camkk2 $2^{-1-}$ mice after $48 \mathrm{~h}$ (Fig. 4B). These data show that both Camk4 $4^{-1-}$ and Camkk2 $2^{-I-}$ mice demonstrate marked phenotypic similarities in which GCPs ap- 
pear to migrate in the appropriate direction but display significantly slower migration, which would result in fewer mature granule cells in the IGL of adult mice. These data strongly suggest that CaMKK2 and CaMKIV are two components of a signaling pathway involved in regulating GCP development and migration between the EGL and IGL.

\section{Impaired CGC migration in vitro}

To further analyze this migration delay in Camk $4^{-1-}$ and Camkk2 $2^{-1-}$ mice, it was evaluated in vitro in cerebellar microexplant cultures from P3 mice as this technique has proven to be a biologically relevant tool for studying proliferation and migration of GCPs (Nagata and Nakatsuji, 1990). Micro-explant cultures from P3 mice were grown for $7 \mathrm{~d}$ on polyD-lysine and laminin-coated coverslips in basal media and viewed by light microscopy. Figure $5 A$ demonstrates that after $7 \mathrm{~d}$, the WT explants exhibited a radial pattern of development characterized by numerous neurite outgrowths and migration of GCPs along these neurite extensions, as previously reported (Nagata and Nakatsuji, 1990). Explants from either the Camk $4^{-1-}$ and Camkk2 $2^{-1-}$ mice also produced a radial pattern of development which recapitulates our in vivo findings that foliation and laminar development of the cerebella from both Camk4 $4^{-1-}$ or Camkk2 $2^{-1-}$ are normal. However, the Camk4 $4^{-1-}$ or Camkk2 $2^{-1-}$ explants did exhibit a significant decrease in the distance of GCP migration compared with WT (Fig. 5A, B). These data support our initial findings suggesting that GCPs from Camk4 ${ }^{-1-}$ or Camkk2 ${ }^{-1-}$ mice have a migration defect in vivo and show that the migration defect can be reproduced in vitro using micro-explants.

Studies have shown that neurotrophins are required for neuronal migration (Borghesani et al., 2002; Polleux et al., 2002; Yamauchi et al., 2003). Since neurotrophins are secreted factors, and our micro-explant data suggest that there may be some factor produced by WT microexplants but not by micro-explants from Camk $4^{-1-}$ or the Camkk2 $2^{-1-}$ mice, we evaluated whether the addition of conditioned medium derived from WT microexplants could rescue the migration defects exhibited by explants from null mice (Fig. 5A). Indeed, WT-conditioned medium did partially rescue GCP migration in freshly isolated micro-explants from both $\mathrm{Camk}^{-1-}$ and Camkk2 $2^{-1-}$ mice, compared with Camk4 ${ }^{-1-}$ or Camkk2 ${ }^{-1-}$ micro-explants that did not receive conditioned media (Fig. $5 B)$. To test whether this partial rescue of migration was attributed specifically to the addition of WT conditioned media,

B
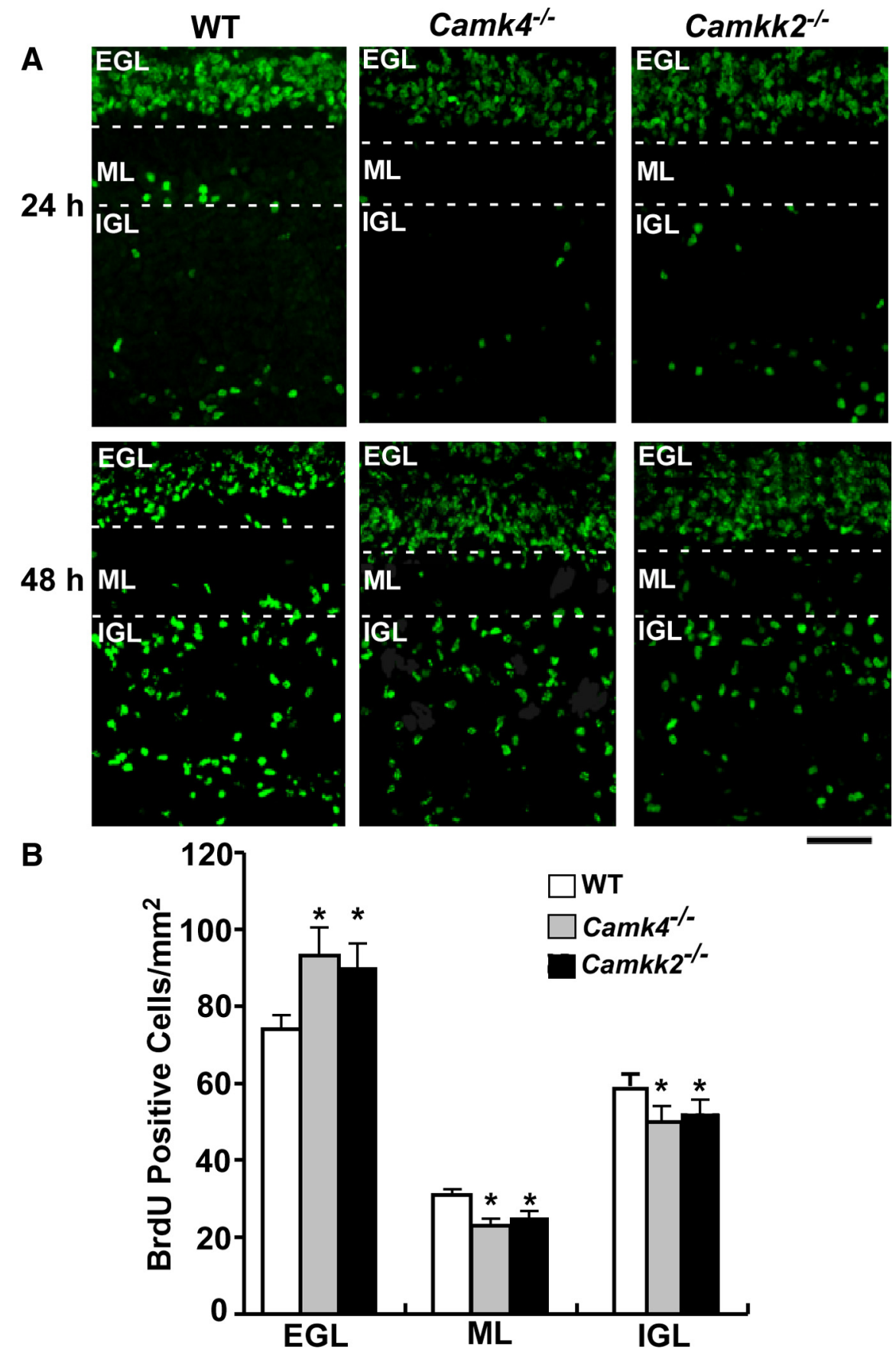

Figure 4. In vivo analysis of migrating granule cells. A, Proliferating GCPs in P7 WT, Camk4 ${ }^{-1-}$, and Camkk2 $2^{-1-}$ mice were labeled by systemic injection of $50 \mathrm{mg} / \mathrm{kg}$ BrdU. Cerebella were then collected and processed for BrdU immunohistochemistry at 24 and $48 \mathrm{~h}$ after injection. DAPI stain (data not shown) was used to aid in identification of each cellular layer (scale bar, $50 \mu \mathrm{m}$ ). B, Quantification of BrdU-labeled GCPs at $48 \mathrm{~h}$ within the three layers of the developing cerebellum. The number of labeled cells in each layer of the cerebellum (EGL, ML, and IGL) was counted in nonadjacent mid-sagittal sections and averaged. Both Camk4 $4^{-1-}$ and Camkk2 $2^{-1-}$ mice have a significant increase in the number of BrdU-labeled cells which have not migrated out of the EGL and a significant decrease in the number of cells which have migrated to the ML and IGL. Values shown are mean \pm SEM $\left({ }^{*} p<0.05\right.$ for difference against WT; $n=4$ mice from each genotype). we also made conditioned media from the Camk4 ${ }^{-1-}$ and Camkk2 ${ }^{-1-}$ micro-explants and put these mediums on the Camkk2 ${ }^{-1-}$ and Camk4 ${ }^{-1-}$ micro-explants, respectively. We found that addition of conditioned medium derived from either null micro-explant did not rescue the migration defect, as did the WT-conditioned medium (Fig. $5 C, D$ ). This partial restoration of long-distance GCP migration in the null micro- 
A

WT
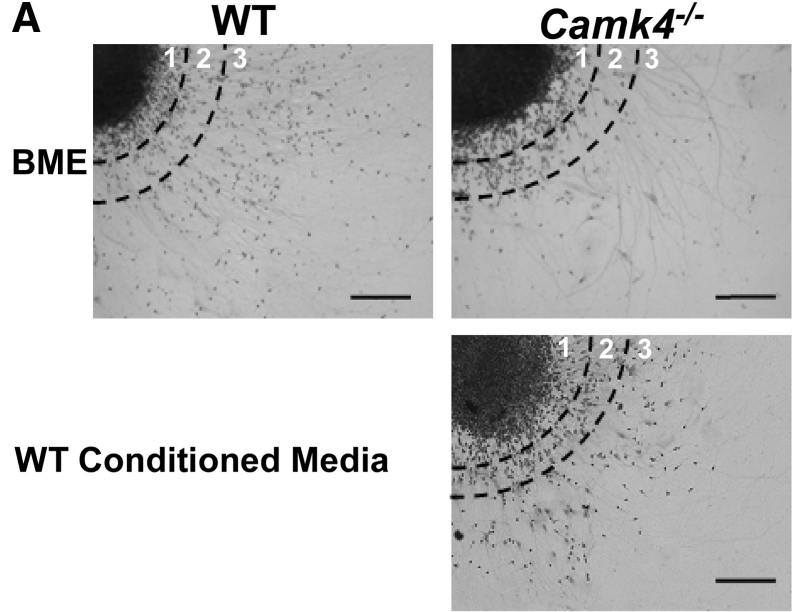

WT Conditioned Media

B

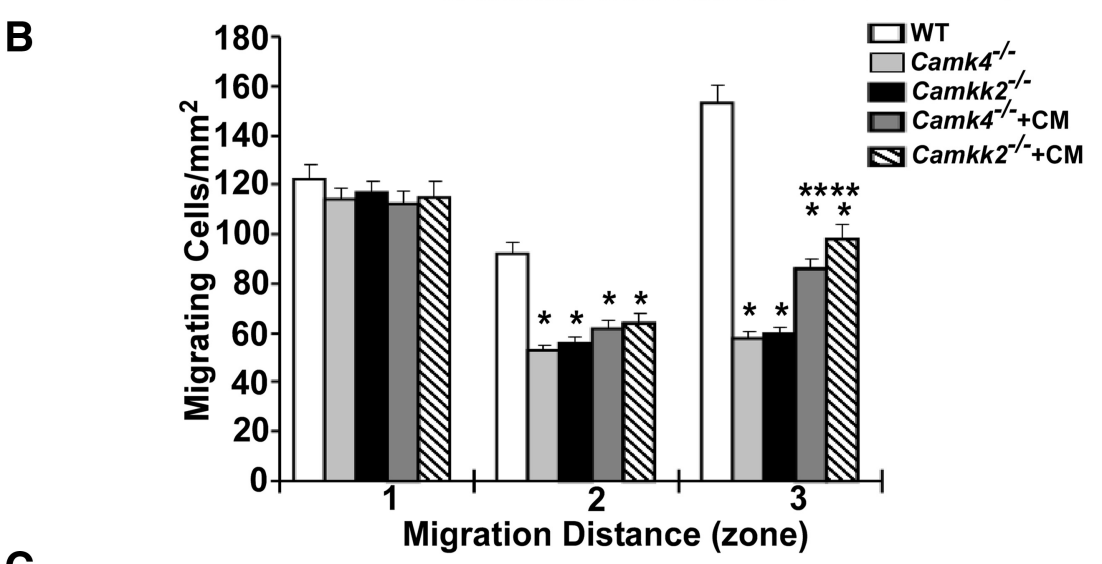

C

KO Conditioned Media
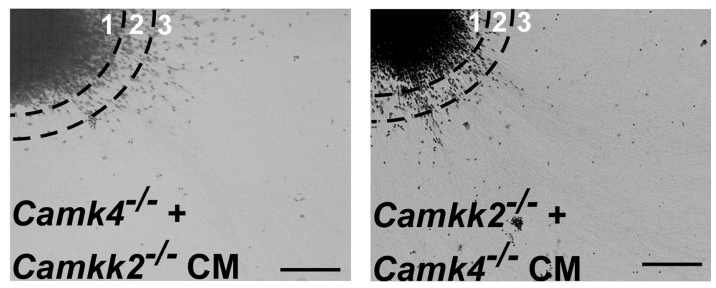

D

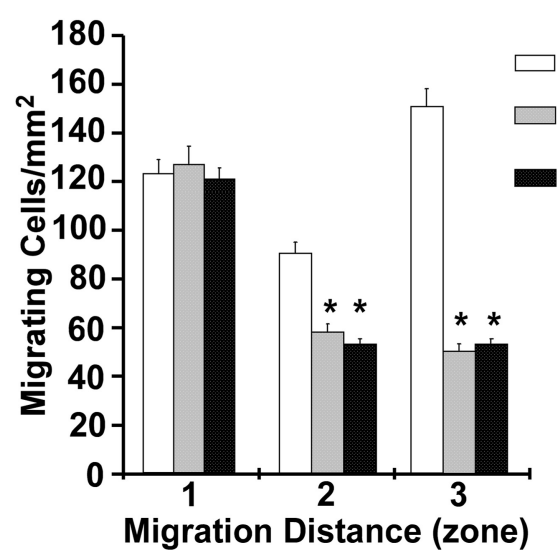

Figure 5. In vitro analysis of wild-type, Camk $4^{-1-}$, and Camkk2 $2^{-1-}$ cerebella using micro-explants. $\boldsymbol{A}$, Cerebellar microexplants derived from $\mathrm{P} 3$ mice were cultured in vitro. The top panel shows representative micro-explants from the three genotypes and reveal a reduction in the ability of GCPs from the Camk $4^{-1-}$ and Camkk2 ${ }^{-1-}$ micro-explants to migrate as far as those from wild type (zone $1=0-100 \mu \mathrm{m} ; z$ ne $2=100-200 \mu \mathrm{m}$; zone $3=200 \mu \mathrm{m}$ and beyond). The bottom panel shows a representative set of micro-explants where conditioned medium removed from WT micro-explants was used instead of fresh media in the cultures of $\mathrm{Camk4}^{-/-}$and Camkk2 $2^{-1-}$ micro-explants. Use of the conditioned medium partially rescues the migration defect (scale bars, $200 \mu \mathrm{m}$ ). B, Quantification of the number of GCPs which have migrated to specified distances (zone1 $=0-100 \mu \mathrm{m}$; zone $2=100-200 \mu \mathrm{m} ;$ zone $3=200 \mu \mathrm{m}$ and beyond). There is a significant reduction in the number of GCPs from both null micro-explants that migrate further than $100 \mu \mathrm{m}$ in fresh medium. Addition of the conditioned medium to both null microexplants significantly improves cellular migration compared with the null micro-explants that received fresh medium. explants only by the WT-conditioned medium suggested the possibility that a secreted cerebellar neurotrophin required for proper migration was decreased or missing in both null mice.

\section{Addition of BDNF restores the ability of null GCPs to migrate in vitro}

Of all the neurotrophins, BDNF is the most studied and has been shown to affect GCP survival, as well as to initiate and regulate the direction of migration of these cells from the EGL. We wanted to test whether BDNF was the secreted neurotrophin missing from the null mice and, as a first step, added recombinant BDNF to micro-explant cultures of cerebella derived from WT, $C a m k 4^{-1-}$, or Camkk2 $2^{-1-}$ mice. As seen previously, micro-explants from WT mice produced a radial pattern of migration, in which significantly more of the GCPs migrated to the furthest distance than did cells from either the Camk4 $4^{-1-}$ or Camkk2 $2^{-1-}$ explants (Fig. 6A, B). Consistent with the evidence that BDNF is rate-limiting for the process by which GCPs are cued to exit the cell cycle and begin to migrate (Borghesani et al., 2002), in WT micro-explants, the addition of recombinant BDNF (100 ng/ $\mathrm{ml}$ ) produced a significant increase in the number of GCPs which had migrated the greatest distance (Fig. $6 A, B$ ). The addition of exogenous BDNF also rescued the migration defect in both $\mathrm{Camk}^{-1-}$ and Camkk2 ${ }^{-1-}$ micro-explants, restoring GCP migration to that characteristic of the untreated WT micro-explants (Fig. 6A, B). Conversely, blocking the actions of BDNF by the addition of TrkB-Fc to WT microexplants resulted in a migration pattern which mirrored that of either the Camk4 $4^{-1-}$ and Camkk2 $2^{-1-}$ microexplants (Fig. 6A, B). These results supported the premise that decreased production of BDNF by developing CGCs in either the Camk4 $4^{-I-}$ or

This conditioned medium, however, only partially restores the ability of cells from either null micro-explant to migrate as far as does the WT cells. $C$, Representative set of micro-explants where conditioned medium removed from Camk $4^{-1-}$ and Camkk2 ${ }^{-I-}$ micro-explants and placed on cultures of Camkk2 $2^{-1-}$ and Camk4 ${ }^{-1-}$ micro-explants, respectively. D, Quantification showing that conditioned medium from Camk4 $4^{-I-}$ micro-explants does not rescue Camkk2 $2^{-1-}$ micro-explants and vice versa. Values shown are mean \pm SEM ${ }^{*} p<0.01$ for nonconditioned and conditioned medium difference against WT; ${ }^{* *} p<0.05$ for Camk4 $4^{-1-}$ and Camkk2 $^{-1-}$ conditioned medium difference against Camk4 ${ }^{-1-}$ and Camkk2 $^{-1-}$ nonconditioned medium; $n=$ 4 for each genotype). 
Camkk2 ${ }^{-1-}$ mice could be at least partially responsible for the migration defect.

Reduced BDNF protein and $m R N A$ in CGCs of Camk4 ${ }^{-/-}$and Camkk2 ${ }^{-/-}$mice Since addition of BDNF restored GCP migration, we next evaluated $B d n f$ mRNA and protein levels directly in GCPs from WT, Camk4 ${ }^{-1-}$, or Camkk2 $2^{-1-}$ mice using isolated primary GCPs, as culturing these cells has been used successfully as an in vitro model to evaluate CGC development. As was seen both in vivo and in cerebellar micro-explants, isolated GCPs do not exhibit overt differences in morphology as determined by phase contrast microscopy (supplemental Fig. 2A, available at www.jneurosci.org as supplemental material). In contrast, immunostaining isolated GCPs that had been cultured for $48 \mathrm{~h}$ with an anti-BDNF antibody revealed considerably less fluorescence in cells from Camk4 $4^{-1-}$ and Camkk2 $2^{-1-}$ mice relative to those from WT mice, and quantification of the fluorescent signal demonstrated that BDNF levels were reduced in the Camk4 $4^{-1-}$ and Camkk2 ${ }^{-1-}$ GCPs by $\sim 50 \%$ (supplemental Fig. $2 B$, available at www.jneurosci.org as supplemental material). To confirm this reduction of BDNF, we quantified the neurotrophin produced from GCPs by ELISA. Indeed, whereas the WT cells contained $1.2+/-$ $0.2 \mathrm{pg}$ of $\mathrm{BDNF} / \mathrm{ng}$ protein, the value in $\mathrm{Camk}^{-1-}$ and Camkk2 ${ }^{-1-}$ GCPs was similarly reduced to $0.4 \pm 0.01 \mathrm{pg} / \mathrm{ng}$ protein $(p<0.001$ relative to WT) (Fig. 7A).

Since BDNF protein levels are significantly reduced in the null mice, we next examined mRNA transcripts by quantitative real-time PCR to determine whether this defect arose at the mRNA level. The most recent data concerning the organization of the mouse $B d n f$ gene suggests that it is composed of eight $5^{\prime}$ exons, each with a specific promoter, that are individually spliced to a common 3' exon that contains the entire coding region of the protein (Aid et al. 2007). Our initial analysis was restricted to the coding exon (now called exon IX), as it is common to all of the $B d n f$ transcripts, and found a significant $20 \%$ reduction in the amount of total $\mathrm{B} d n f$ mRNA in both Camk4 ${ }^{-1-}$ and Camkk2 $2^{-1-}$ GCPs relative to WT (Fig. 7B). We next examined mRNA derived from the $B d n f$ promoters shown to be responsive to increases in intracellular $\mathrm{Ca}^{2+}$ (Shieh et al. 1998; Tao et al., 1998, 2002; Tabuchi et al., 2002; Chen et al., 2003), as this is the most likely stimulus to activate a CaM kinase cascade. In the new nomenclature, the two most highly expressed $B d n f$ gene transcripts that respond to $\mathrm{Ca}^{2+}$ stimulation are those derived from genotype).
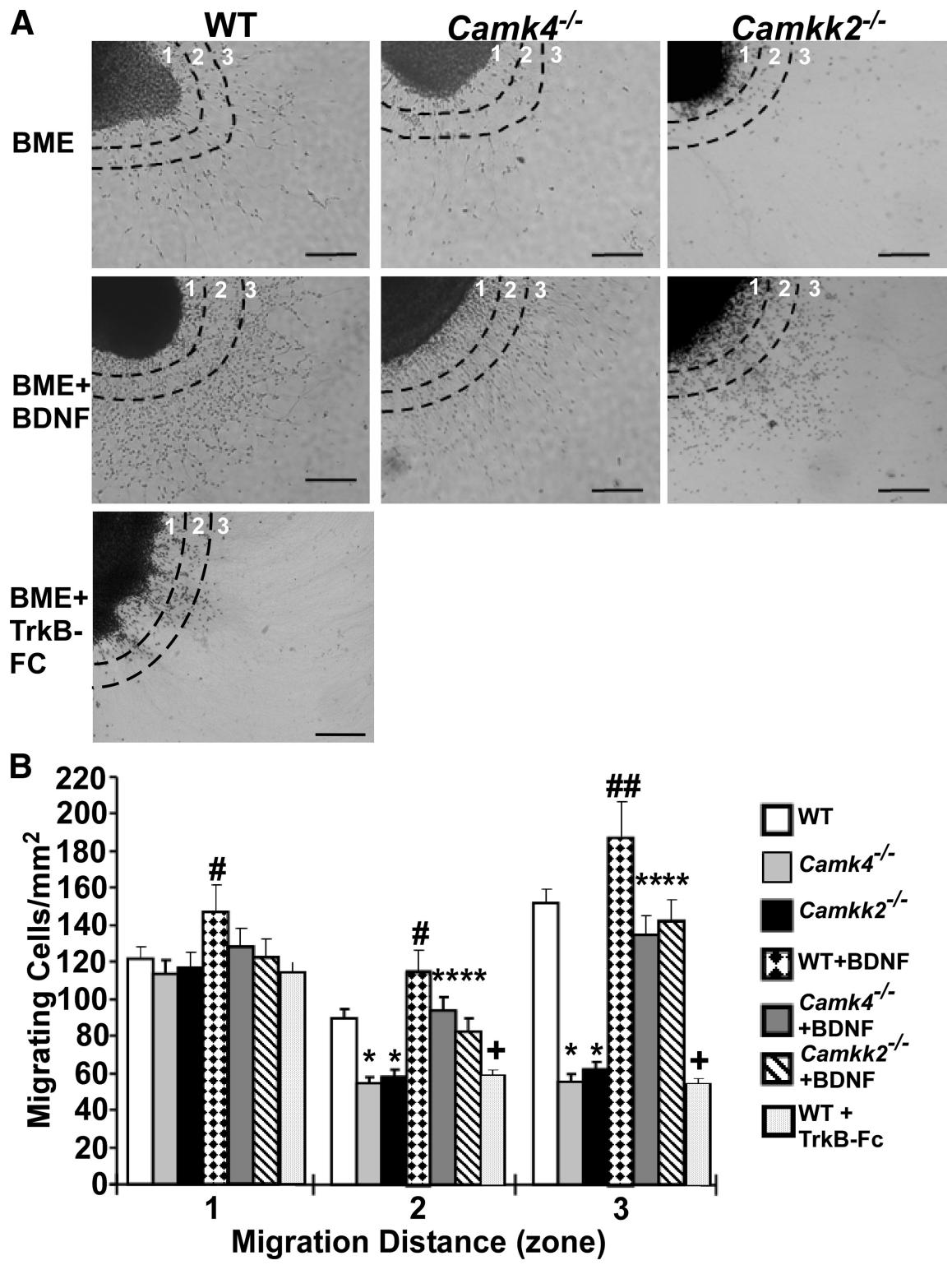

Figure 6. Addition of exogenous BDNF to cerebellar micro-explants restores GCP migration. $A$, The top panel shows representative micro-explants from the three genotypes again revealing a reduction in the ability of GCPs from the Camk $4^{-1-}$ and Camkk2 $^{-1-}$ micro-explants to migrate as far as those from WT (zone1 $=0-100 \mu \mathrm{m} ;$ zone $2=100-200 \mu \mathrm{m} ;$ zone $3=200$ $\mu \mathrm{m}$ and beyond). The addition of exogenous BDNF (middle panel) rescues both null explants by restoring migration of GCPs to levels seen in WT, which did not received exogenous BDNF. Addition of TrkB-Fc blocks the migration of WT explants and mirrors migration of that seen in both the Camk4 $4^{-1-}$ and Camkk2 ${ }^{-1-}$ micro-explants (scale bars, $200 \mu \mathrm{m}$ ). B, Quantification of the number of GCPs which have migrated to specified distances (zone1 = 0-100 $\mu \mathrm{m}$; zone $2=100-200 \mu \mathrm{m}$; zone $3=200 \mu \mathrm{m}$ and beyond). As demonstrated in the previous figure, there is a significant reduction in the number of GCPs from both null micro-explants that migrate further than $100 \mu \mathrm{m}$ in basal media. Addition of the media containing BDNF ( $100 \mathrm{ng} / \mathrm{ml})$ to both null micro-explants significantly improves migration to normal levels seen in WT micro-explants, which did not receive exogenous BDNF. The addition of exogenous BDNF also results in an increase in migrating cells in the WT micro-explant. Addition of TrkB-Fc inhibits BDNF mediated migration in WT micro-explants. Values shown are mean \pm SEM $\left({ }^{*} p<0.01\right.$ for difference against WT; ${ }^{* *} p<0.01$ for difference of Camk4 ${ }^{-1-}$ and Camkk2 ${ }^{-1-}+$ BDNF vs Camk4 ${ }^{-1-}$ and Camkk2 ${ }^{-1-},{ }^{\#} p<0.05,{ }^{\# \#} p<0.01$ for difference of WT + BDNF against WT and ${ }^{+} p<0.01$ for difference of WT + TrkB-Fc against WT; $n=4$ for each experimental

exon I and exon IV (Aid et al. 2007). As shown in Figure 7C, mRNA derived from exon I was significantly reduced in isolated Camk4 $4^{-1-}$ and Camkk2 ${ }^{-1-}$ CGCs by $42 \%$ compared with WT CGCs, and mRNA derived from exon IV was also significantly reduced by $30 \%$ in $\mathrm{Camk}^{-1-}$ and $42 \%$ in Camkk2 ${ }^{-1-}$ CGCs, respectively. These results demonstrate that in the absence of either CaMKIV or CaMKK2, there is decreased mRNA produc- 
A
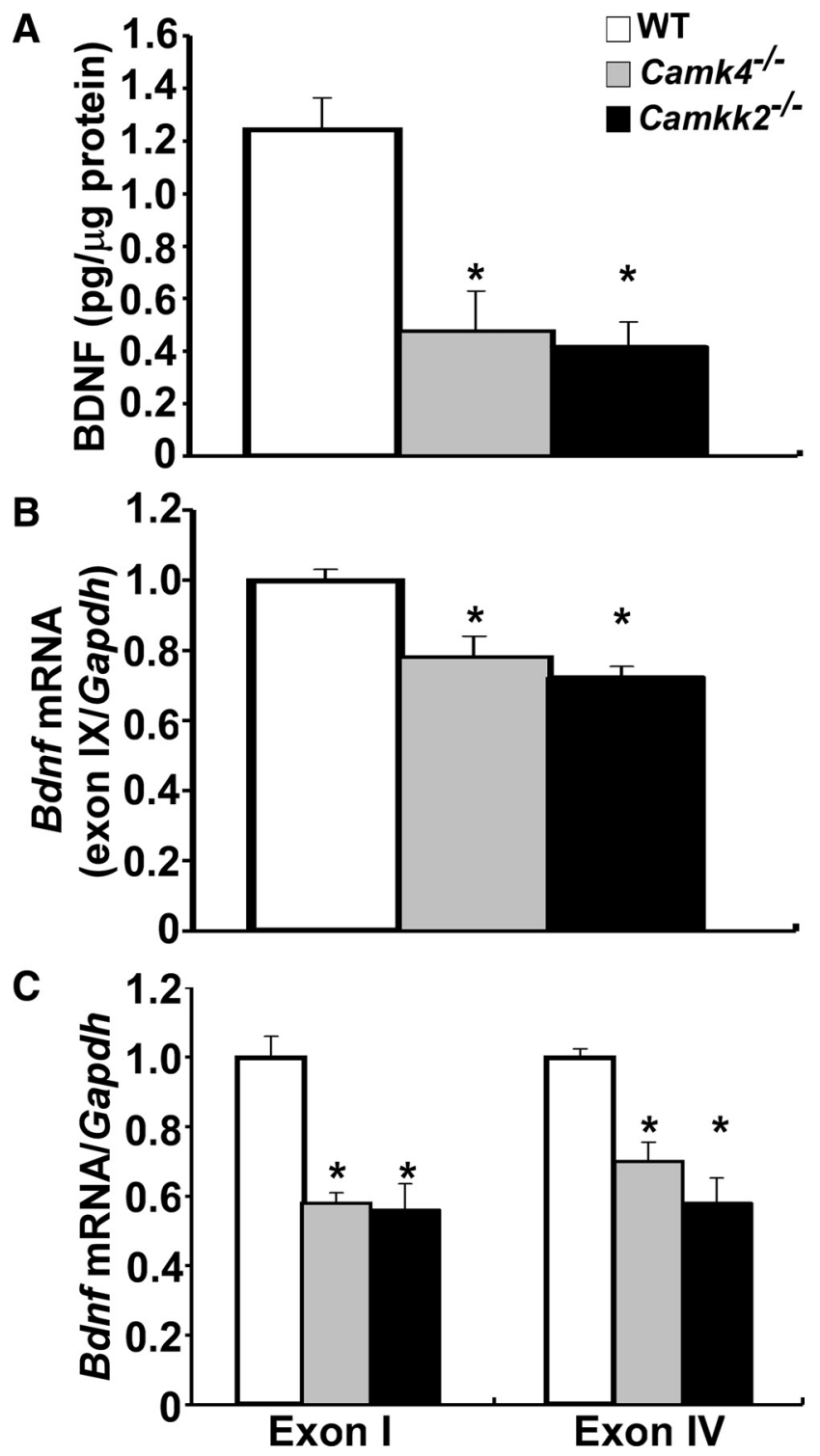

Figure 7. BDNF protein and mRNA are reduced in both Camk4 $4^{-1-}$ and Camkk2 $2^{-1-}$ mice. $A$, ELISA quantification of BDNF in freshly isolated GCP extracts. Values shown are mean \pm SEM $\left({ }^{*} p<0.01\right.$ for difference against WT; $n=6$ for each genotype). $\boldsymbol{B}$, Real-time PCR analysis of total Bdnf mRNA in freshly isolated GCPs. Values shown are mean \pm SEM $\left({ }^{*} p<0.05\right.$ for difference against WT; $n=7$ for each genotype). $C$, Real-time P(R analysis of $B d n f$ mRNA in freshly isolated GCPs using specific primers to detect transcripts derived from either exon I or exon IV. Values shown are mean \pm SEM $\left({ }^{*} p<0.01\right.$ for difference against WT; $n=7$ for each genotype).

tion derived from two known $\mathrm{Ca}^{2+}$ sensitive $B d n f$ promoters that conspire to reduce the production of BDNF protein.

Promoters I and IV in the Bdnf gene contain CRE elements that are regulated by CREB, which has been phosphorylated at Ser ${ }^{133}$ (pCREB). As CaMKIV can induce CREB phosphorylation at $\operatorname{Ser}^{133}$ (Matthews et al., 1994) and we have previously demonstrated a significant reduction of the phosphorylated form of this transcription factor in the whole cerebellum of Camk4 $4^{-1-}$ mice (Ribar et al. 2000), we examined pCREB in isolated GCPs from Camk4 $4^{-1-}$ and Camkk2 $2^{-1-}$ mice. The amount of basal pCREB fluorescence intensity was reduced in the GCPs from Camk4 ${ }^{-1-}$ relative to WT mice (supplemental Fig. 2A, available at www. jneurosci.org as supplemental material), and quantification of the signal revealed approximately a 50\% decrease from WT levels (supplemental Fig. 2C, available at www.jneurosci.org as supplemental material). The GCPs from Camkk2 ${ }^{-1-}$ mice showed a similar reduction in basal pCREB immunofluorescent signal (supplemental Fig. $2 \mathrm{~A}$, available at www.jneurosci.org as supplemental material), which quantification also revealed to be $50 \%$ less than WT (supplemental Fig. 2C, available at www.jneurosci.org as supplemental material). These data suggest that in GCPs, the reduction in pCREB presages the decrease in Bdnf mRNA and BDNF protein attributable to the absence of CaMKK2 or CaMKIV.

\section{Reexpression of active CaMKIV or CaMKK2 restores pCREB and BDNF}

If CaMKK2 and CaMKIV are components of the $\mathrm{Ca}^{2+}$-sensitive pathway that phosphorylates CREB on $\operatorname{Ser}^{133}$ and leads to the expression of BDNF, then reexpression of CaMKIV in freshly isolated GCPs from Camk4 $4^{-1-}$ mice or CaMKK2 in freshly isolated GCPs from Camkk2 $2^{-1-}$ mice should restore pCREB and BDNF levels to those characteristic of WT GCPs. To test this, GCPs from Camk4 $4^{-1-}$ mice were plated and left uninfected or infected with lentiviral constructs that expressed an empty vector, a full-length CaMKIV cDNA, or a mutant cDNA to express a kinase-inactive form of CaMKIV. Likewise, GCPs from the Camkk2 $2^{-1-}$ mice were plated and left uninfected or infected with lentiviral vectors expressing an empty vector, CaMKK2, or an inactive form of CaMKK2. Three days after infection, protein levels for CaMKIV, CaMKK2, BDNF, pCREB, and CREB were evaluated with immunoblotting. We found that in uninfected CGCs derived from either Camk4 ${ }^{-1-}$ or Camkk2 ${ }^{-1-}$ mice, there is reduced expression level of both BDNF and pCREB but no difference in total CREB (Fig. 8A, C). Western blots showing only uninfected controls are presented because we found that expression of the empty lentiviral vectors in either WT, Camk4 ${ }^{-l-}$, or Camkk2 $2^{-1-}$ GCPs did not alter CREB, pCREB, or BDNF protein levels compared with either WT, Camk4 $4^{-1-}$, or Camkk2 $2^{-1-}$ GCPs, which were uninfected and did not affect the results. Lentiviral-mediated expression of active CaMKIV in GCPs from Camk4 $4^{-1-}$ mice, however, restored $\mathrm{PCREB}$ and BDNF protein to near WT levels, whereas expression of the kinase-inactive CaMKIV did not (Fig. 8A, B). Similarly, lentiviral-mediated expression of active CaMKK2 in GCPs from Camkk2 $2^{-1-}$ mice also restored $\mathrm{pCREB}$ and $\mathrm{BDNF}$ protein to WT levels, whereas expression of the kinase-inactive CaMKK2 did not (Fig. 8C, D). Collectively, these results support our contention that both CaMKK2 and CaMKIV are components of $\mathrm{C} \mathrm{Ca}^{2+}$-signaling pathway present in GCPs that increase pCREB and, in turn, the production of BDNF.

\section{Discussion}

In the cerebellum, granule cells and Purkinje cells (PCs) develop synergistically, and alterations in the developmental program of either cell type affects the other (Herrup et al., 1996; Morrison and Mason, 1998). Earlier studies showed that the absence of CaMKIV results in abnormal PCs, characterized by a decreased number of mature cells together with stunted arborization and altered parallel fiber synaptic currents of the remaining cells (Ho et al., 2000; Ribar et al., 2000). We hypothesized that these adult defects may arise from developmental issues involving CGCs in addition to PCs, as PCs only express CaMKIV during a brief period between late embryogenesis and early postnatal development, whereas CGCs express both CaMKIV and its upstream activator CaMKK2 from early postnatal development through adulthood (Ohmstede et al., 1989; Jensen et al., 1991; Vinet et al., 2003; Sato et al., 2006). Utilizing mice null for Camkk2 or Camk4, 
we find that both strains show a defect in the ability of developing GCPs to cease proliferation in the EGL and migrate to the IGL. CREB phosphorylation is reduced in GCPs, and we show that deletion of either Camk4 or Camkk2 is associated with reduced expression of the CREB target gene Bdnf in these cells. Given the evidence that BDNF plays essential roles in development of the cerebellum, these data are consistent with the possibility that the cerebellar abnormalities we observe in the Camk4 and Camkk2 null mice arise at least in part through impairment of BDNFdependent processes.

BDNF is an abundant and widely distributed neurotrophin that not only promotes neuronal survival during development (Lindholm et al., 1993), but also supports neurite outgrowth (Segal et al., 1995; Jin et al., 2003) and synapse development (Hong et al., 2008). Several lines of evidence suggest that BDNF is crucial for the migration and differentiation of GCPs in the cerebellum. During cerebellar development, the EGL constitutes a mitogenic niche that supports the proliferation of GCPs (Choi et al., 2005). BDNF not only acts as a chemokinetic factor to induce the migration of GCPs away from the EGL (Borghesani et al., 2002), but cellautonomous expression of BDNF by GCPs also signals in an autocrine manner to amplify the ambient EGL to IGL gradient of BDNF, and coordinate the directionality of GCP migration (Zhou et al., 2007). Lacking this cue, $B d n f^{-1-}$ mice have a marked delay in the migration of GCPs and increased thickness in the EGL resulting from continued proliferation (Borghesani et al., 2002; Jones et al., 1994). These effects on GCPs in $B d n f$ null cerebellum are associated with reducing signaling through TrkB receptors in GCPs (Qiao et al., 1998; Borghesani et al., 2002), and are phenocopied in Trkb null mice (Minichiello and Klein 1996; Rico et al., 2002). In the absence of either CaMKK2 or CaMKIV, developing GCPs in the EGL exhibit a strikingly similar phenotype to that seen in the absence of BDNF. GCPs in Camk4 and Camkk2 null mice show increased proliferation and apoptosis at P7 (Fig. 3), as well as delayed migration from the EGL (Fig. 4). We show that the delayed migration of the GCPs from Camkk2 $2^{-1-}$ or Camk $4^{-1-}$ mice can be recapitulated in vitro using cerebellar micro-explants (Fig. 5). However, by adding conditioned medium from wild-type cells (Fig. 5) or exogenous BDNF (Fig. 6), the migration defect is rescued. These results confirm that the TrkB-receptor signaling pathway
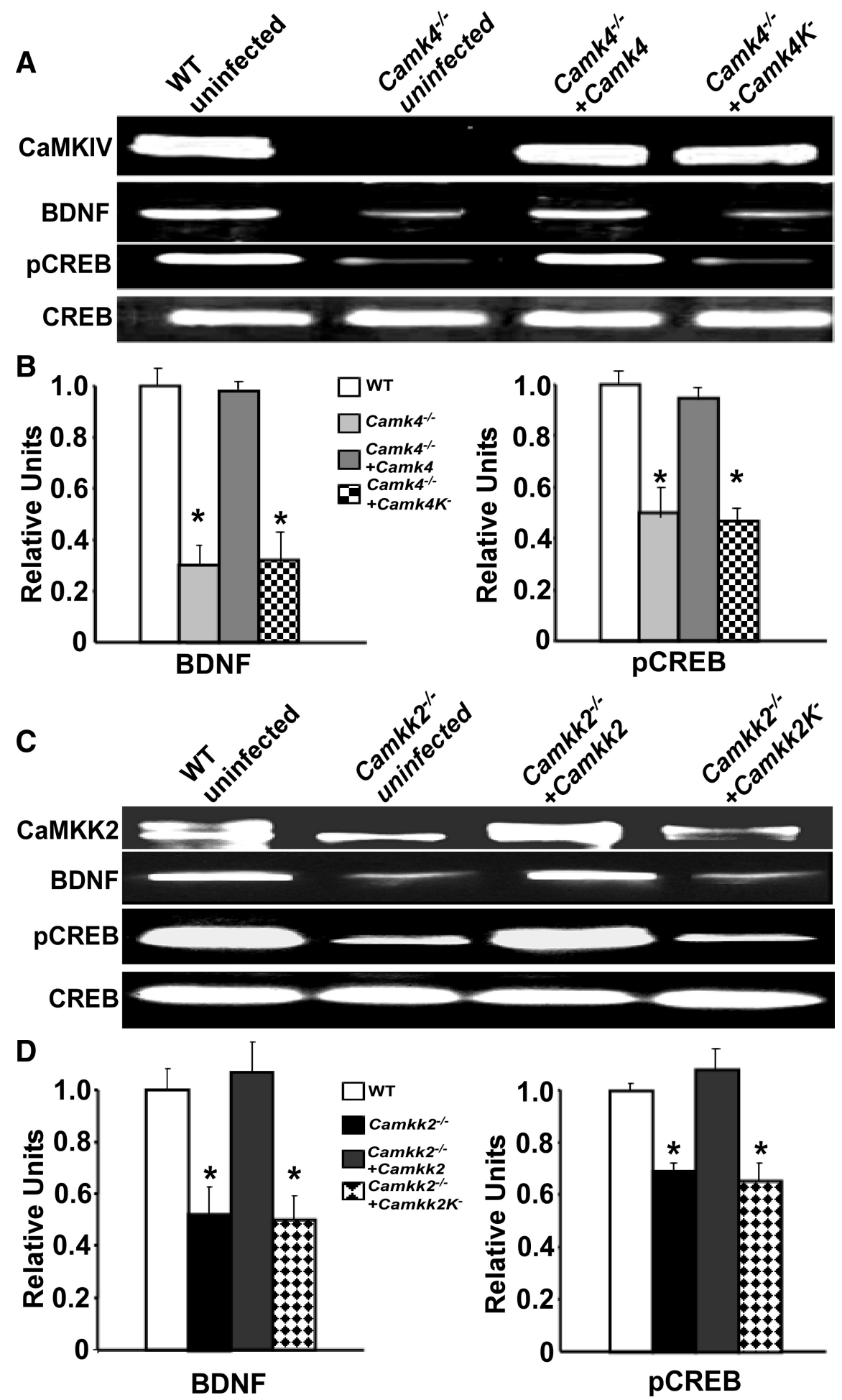

Figure 8. Lentiviral-mediated reexpression of CaMKIV or CaMKK2 restores pCREB and BDNF. $\boldsymbol{A}$, Representative immunoblot of protein extracts derived from cultured WT and Camk4 ${ }^{-1-}$ GCPs or Camk4 ${ }^{-1-}$ GCPs which have been left uninfected, infected with either a lentiviral-CaMKIV-WT (active) or lentiviral-CaMKIV-K71M (inactive) construct. Note lower level of BDNF and pCREB in Camk4 ${ }^{-1-}$ GCPs. The reexpression of a catalytically active form of CaMKIV restored both BDNF and pCREB levels, whereas expression of the catalytically inactive CaMKIV-K71M did not restore BDNF or pCREB levels. B, Quantification of immunoblots after normalizing to total CREB (values shown are mean \pm SEM; ${ }^{*} p<0.01$ for difference against WT; $n=4$ independent experiments). C, Representative Western blot analysis of protein extracts derived from cultured WT and Camkk2 ${ }^{-1-}$ GCPs or Camkk2 $2^{-1-} \mathrm{GCPs}$, which have been left uninfected or infected with either a lentiviral-CaMKK2-WT (active) or lentiviral-CaMKK2-K193E (inactive) construct. The lower molecular weight band seen so prominently in the Camkk2 ${ }^{-1-}$ lane is CaMKK1. Note that there is also reduced BDNF and pCREB protein in Camkk2 ${ }^{-1-}$ GCPs. The reexpression of a catalytically active form of CaMKK2 also restored both BDNF and pCREB levels, whereas expression of the catalytically inactive CaMKK2K193E did not restore BDNF or pCREB levels. $B$, Quantification of immunoblots after normalizing to total CREB (values shown are the mean \pm SEM; ${ }^{*} p<0.05$ for difference against WT; $n=3$ independent experiments). 
remains viable when either CaMKK2 or CaMKIV is absent, and demonstrate that this kinase cascade acts upstream of BDNF binding to TrkB receptors.

As we observed in the Camk4 nulls, we find that PCs in the Camkk2 knock-out mice have stunted dendritic arbors (supplemental Fig. 1, available at www.jneurosci.org as supplemental material). One possibility is that this phenotype may arise as a consequence of altered CGC development and BDNF secretion. Studies on one strain of $B d n f$ null mice have indicated that BDNF synthesized by CGCs may act as an anterograde trophic factor to promote the development and/or maintenance of PC dendrites and synapses (Schwartz et al., 1997; Carter et al., 2002) (but see Jones et al., 1994). However, stunted dendritic arbors have also been observed in PCs of mice with mutations unrelated to BDNF signaling, including the naturally occurring Lurcher (Grid2) and Staggerer (Ror $\alpha$ ) strains (Soha and Herrup, 1995). Thus, although reductions in BDNF-TrkB signaling seem likely to contribute to cerebellar defects in Camk4 and Camkk2 knock-out mice, additional studies will be needed to address the relative contributions of additional targets of this signaling pathway.

Both BDNF and CaMKIV exert prosurvival functions. In neurons, BDNF signaling through $\operatorname{TrKB}$ inhibits apoptosis through the MAP and PI-3 kinase/AKT pathways (Zhu et al., 2005; Zheng et al., 2008). CaMKIV has a prosurvival role in multiple cell types including CGCs (Sée et al. 2001), rat spiral ganglion neurons (Bok et al. 2007), chicken spinal cord motor neurons (Pérez-García et al., 2008), hematopoietic stem cells (HSCs) (Kitsos et al., 2005), and dendritic cells (Illario et al., 2008). In HSCs and dendritic cells, CaMKIV regulates CREB phosphorylation and transcriptional regulation of the prosurvival protein Bcl-2; however, the manner by which CaMKIV exerts an anti-apoptotic effect in neurons is less understood. In both CGCs and cultured rat spiral ganglion neurons, the loss of $\mathrm{Ca}^{2+} / \mathrm{CaMKIV}$-dependent CREB phosphorylation is correlated with increased apoptosis (Sée et al. 2001; Bok et al. 2007) and acts either through the upregulation of BDNF or the transcriptional regulation of Bcl-2 (Bok et al., 2007). Alternatively, in cultured chick motor neurons CaMKIV has been shown to bind in an activity independent manner directly to the p85 regulatory subunit of PI-3 kinase, promoting AKT phosphorylation and preventing the activation of the apoptotic machinery (Pérez-García et al., 2008). Our experiments show that $\mathrm{Bcl}-2$ is not decreased in GCPs isolated from Camk $4^{-1-}$ or Camkk2 $2^{-1-}$ mice (data not shown). Together, these data are most consistent with the possibility that the BDNF pathway is responsible for the prosurvival effects of this kinase cascade in GCPs.

Transcription of $B d n f$ is complex and highly regulated by the activation of intracellular $\mathrm{Ca}^{2+}$-signaling pathways. Promoters I and IV are highly induced by $\mathrm{Ca}^{2+}$ signaling (Timmusk et al., 1993; Aid et al., 2007), and both of these promoters can be bound by the $\mathrm{Ca}^{2+}$-activated transcription factor CREB (Shieh et al., 1998; Tao et al., 1998, 2002; Tabuchi et al., 2002; Chen et al., 2003; Hong et al., 2008). Although many kinases, including CaMKIV, can phosphorylate CREB at Ser ${ }^{133}$ (Matthews et al., 1994; Finkbeiner, 2000; Mayr and Montminy 2001), it has remained controversial which kinases are physiologically required for $\mathrm{Ca}^{2+}$-regulated CREB-dependent transcription in neurons (Wayman et al., 2008). Because several in vitro studies have shown that CaMKIV mediates transient phosphorylation of CREB, whereas MAP kinase signaling is required for prolonged CREB phosphorylation (Dolmetsch et al., 2001; Wu et al., 2001), it had been suggested that MAP kinase-dependent phosphoryla- tion might be more relevant for the activation of CREBdependent transcription. However, studies have demonstrated that CaMKIV is required in vivo for several activity- and transcription-dependent processes including long-term memory (Kang et al., 2001; Wei et al., 2002) and cell survival (Sée et al., 2001; Lee et al., 2005). Previously, we and others demonstrated that Camk4 ${ }^{-1-}$ mice show significantly reduced levels of CREB Ser ${ }^{133}$ phosphorylation (Ho et al., 2000; Ribar et al., 2000). We find a similar reduction in CREB phosphorylation at $\operatorname{Ser}^{133}$ in the GCPs of Camkk2 $2^{-1-}$ mice (supplemental Fig. 2, available at www.jneurosci.org as supplemental material). In the absence of either CaMKK2 or CaMKIV, GCPs exhibit significantly reduced levels of $B d n f$ mRNAs derived from the CREBregulated promoters that initiate transcription of exon I or exon IV (Fig. 7C), and lentiviral add-back of full-length, functional CaMKK2, or CaMKIV restores both $\mathrm{pCREB}$ and BDNF protein to normal levels in cultured GCPs (Fig. 8). This suggests that CaMKK2 and CaMKIV are required components for the $\mathrm{Ca}^{2+}$ - and CREB-dependent transcriptional regulation of the $B d n f$ gene in developing GCPs. In addition, the observation that deletion of CaMKK2 phenocopies the deletion of CaMKIV with respect to pCREB levels, BDNF expression, and GCP migration, strongly suggests that these two kinases are physiologically linked in a single hierarchical pathway to mediate CGC development.

Our data underscore the importance of $\mathrm{Ca}^{2+}$-dependent signaling in regulating GCP development, and identify CaMKK2 and CaMKIV as part of the signaling cascade by which $\mathrm{Ca}^{2+}$ induces BDNF production. We conclude that an increase in intracellular $\mathrm{Ca}^{2+}$ in GCPs activates a signaling module through CaM, CaMKK2 and CaMKIV, which increases CREB phosphorylation and $B d n f$ expression. The resulting increase in BDNF is required to assure the temporally critical progression of the GCPs from proliferation to migration and maturation in the developing cerebellum. Of interest, signaling through TrkB receptors has recently been shown to be required for activity-dependent adult neurogenesis in the dentate gyrus of the hippocampus ( $\mathrm{Li}$ et al., 2008). Thus, whether the CaM-CaMKK2-CaMKIV-pCREBBDNF pathway plays a conserved role in the differentiation and migration of these cells will be an intriguing question for future studies.

\section{References}

Aid T, Kazantseva A, Piirsoo M, Palm K, Timmusk T (2007) Mouse and rat BDNF gene structure revisited. J Neurosci Res 85:525-535.

Altman J, Bayer SA (1997) Development of the cerebellar system: in relation to its evolution, structure and functions. Boca Raton, FL: CRC.

Anderson KA, Ribar TJ, Lin F, Noeldner PK, Green MF, Muehlbauer MJ, Witters LA, Kemp BE, Means AR (2008) Hypothalamic CaMKK2 contributes to the regulation of energy balance. Cell Metab 7:377-388.

Bok J, Wang Q, Huang J, Green SH (2007) CaMKII and CaMKIV mediate distinct prosurvival signaling pathways in response to depolarization in neurons. Mol Cell Neurosci 36:13-26.

Borghesani PR, Peyrin JM, Klein R, Rubin J, Carter AR, Schwartz PM, Luster A, Corfas G, Segal RA (2002) BDNF stimulates migration of cerebellar granule cells. Development 129:1435-1442.

Carter AR, Chen C, Schwartz PM, Segal RA (2002) Brain-derived neurotrophic factor modulates cerebellar plasticity and synaptic ultrastructure. J Neurosci 22:1316-1327.

Chen WG, West AE, Tao X, Corfas G, Szentirmay MN, Sawadogo M, Vinson C, Greenberg ME (2003) Upstream stimulatory factors are mediators of $\mathrm{Ca}^{2+}$-responsive transcription in neurons. J Neurosci 23:2572-2581.

Choi Y, Borghesani PR, Chan JA, Segal RA (2005) Migration from a mitogenic niche promotes cell-cycle exit. J Neurosci 25:10437-10445.

Chow FA, Anderson KA, Noeldner PK, Means AR (2005) The autono- 
mous activity of calcium/calmodulin-dependent protein kinase IV is required for its role in transcription. J Biol Chem 280:20530-20538.

Dolmetsch RE, Pajvani U, Fife K, Spotts JM, Greenberg ME (2001) Signaling to the nucleus by an L-type calcium channel-calmodulin complex through the MAP kinase pathway. Science 294:333-339.

Finkbeiner S (2000) CREB couples neurotrophin signals to survival messages. Neuron 25:11-14.

Greer PL, Greenberg ME (2008) From synapse to nucleus: calciumdependent gene transcription in the control of synapse development and function. Neuron 59:846-860.

Herrup K, Hojaeian-Zanjani H, Panzini L, Sunter K, Mariani J (1996) The numerical matching of source and target populations in the CNS: the inferior olive to Purkinje cell projection. Dev Brain Res 96:28-35.

Ho N, Liauw JA, Blaeser F, Wei F, Hanissian S, Muglia LM, Wozniak DF, Nardi A, Arvin KL, Holtzman DM, Linden DJ, Zhuo M, Muglia LJ, Chatila TA (2000) Impaired synaptic plasticity and cAMP response element-binding protein activation in $\mathrm{Ca}^{2+} /$ calmodulin-dependent protein kinase type IV/Gr-deficient mice. J Neurosci 20:6459-6472.

Hong EJ, McCord AE, Greenberg ME (2008) A biological function for the neural activity-dependent component of Bdnf transcription in the development of cortical inhibition. Neuron 60:610-624.

Huang EJ, Reichardt LF (2001) Neurotrophins: roles in neuronal development and function. Annu Rev Neurosci 24:677-736.

Illario M, Giardino-Torchia ML, Sankar U, Ribar TJ, Galgani M, Vitiello L, Masci AM, Bertani FR, Ciaglia E, Astone D, Maulucci G, Cavallo A, Vitale M, Cimini V, Pastore L, Means AR, Rossi G, Racioppi L (2008) Calmodulin-dependent kinase IV links Toll-like receptor 4 signaling with survival pathway of activated dendritic cells. Blood 111:723-731.

Jensen KF, Ohmstede CA, Fisher RS, Olin JK, Sahyoun N (1991) Acquisition and loss of a neuronal $\mathrm{Ca} 2+/$ calmodulin-dependent protein kinase during neuronal differentiation. Proc Natl Acad Sci U S A 88:4050-4053.

Jin X, Hu H, Mathers PH, Agmon A (2003) Brain-derived neurotrophic factor mediates activity-dependent dendritic growth in nonpyramidal neocortical interneurons in developing organotypic cultures. J Neurosci 23:5662-5673.

Jones KR, Fariñas I, Backus C, Reichardt LF (1994) Targeted disruption of the BDNF gene perturbs brain and sensory neuron development but not motor neuron development. Cell 76:989-999.

Kang H, Sun LD, Atkins CM, Soderling TR, Wilson MA, Tonegawa S (2001) An important role of neural activity-dependent CaMKIV signaling in the consolidation of long-term memory. Cell 106:771-783.

Kitsos CM, Sankar U, Illario M, Colomer-Font JM, Duncan AW, Ribar TJ, Reya T, Means AR (2005) Calmodulin-dependent protein kinase IV regulates hematopoietic stem cell maintenance. J Biol Chem 280:33101-33108.

Komuro H, Yacubova E (2003) Recent advances in cerebellar granule cell migration. Cell Mol Life Sci 60:1084-1098.

Lee B, Butcher GQ, Hoyt KR, Impey S, Obrietan K (2005) Activitydependent neuroprotection and cAMP response element-binding protein (CREB): kinase coupling, stimulus intensity, and temporal regulation of CREB phosphorylation at serine 133. J Neurosci 25:1137-1148.

Li Y, Luikart BW, Birnbaum S, Chen J, Kwon CH, Kernie SG, Bassel-Duby R, Parada LF (2008) TrkB regulates hippocampal neurogenisis and governs sensitivity to antidepressive treatment. Neuron 59:399-412.

Lindholm D, Dechant G, Heisenberg CP, Thoenen H (1993) Brain-derived neurotrophic factor is a survival factor for cultured rat cerebellar granule neurons and protects them against glutamate-induced neurotoxicity. Eur J Neurosci 5:1455-1464.

Lindholm D, Hamnér S, Zirrgiebel U (1997) Neurotrophins and cerebellar development. Perspect Dev Neurobiol 5:83-94.

Matthews RP, Guthrie CR, Wailes LM, Zhao X, Means AR, McKnight GS (1994) Calcium/calmodulin-dependent protein kinases type II and type IV differentially regulate CREB-dependent gene expression. Mol Cell Biol 14:6107-6116.

Mayr B, Montminy M (2001) Transcriptional regulation by the phosphorylation-dependent factor CREB. Nat Rev Mol Cell Biol 2:599-609.

Minichiello L, Klein R (1996) TrkB and TrkC neurotrophin receptors cooperate in promoting survival of hippocampal and granule neurons. Genes Dev 10:2849-2858.
Morrison ME, Mason CA (1998) Granule neuron regulation of Purkinje cell development: striking a balance between neurotrophin and glutamate signaling. J Neurosci 18:3563-3573.

Nagata I, Nakatsuji N (1990) Granule cell behavior on laminin in cerebellar microexplant cultures. Brain Res Dev Brain Res 52:63-73.

Ohmstede CA, Jensen KF, Sahyoun NE (1989) Ca2+/calmodulindependent protein kinase enriched in cerebellar granule cells. Identification of a novel neuronal calmodulin-dependent protein kinase. J Biol Chem 264:5866-5875.

Pérez-García MJ, Gou-Fabregas M, de Pablo Y, Llovera M, Comella JX, Soler RM (2008) Neuroprotection by neurotrophic factors and membrane depolarization is regulated by calmodulin kinase IV. J Biol Chem 283:4133-4144.

Polleux F, Whitford KL, Dijkhuizen PA, Vitalis T, Ghosh A (2002) Control of cortical interneuron migration by neurotrophins and PI-3 kinase signaling. Development 129:3147-3160.

Qiao X, Chen L, Gao H, Bao S, Hefti F, Thompson RF, Knusel B (1998) Cerebellar brain-derived neurotrophic factor-TrkB defect associated with impairment of eyeblink conditioning in Stargazer mutant mice. J Neurosci 18:6990-6999.

Ribar TJ, Rodriguiz RM, Khiroug L, Wetsel WC, Augustine GJ, Means AR (2000) Cerebellar defects in $\mathrm{Ca}^{2+} /$ calmodulin kinase IV deficient mice. J Neurosci 20:RC107 (1-5).

Rico B, Xu B, Reichardt LF (2002) TrkB receptor signaling is required for establishment of GABAergic synapses in the cerebellum. Nat Neurosci 5:225-233.

Rubinson DA, Dillon CP, Kwiatkowski AV, Sievers C, Yang L, Kopinja J, Rooney DL, Zhang M, Ihrig MM, McManus MT, Gertler FB, Scott ML, Van Parijs LA (2003) Lentivirus-based system to functionally silence genes in primary mammalian cells, stem cells and transgenic mice by RNA interference. Nat Genet 33:401-406.

Sato M, Suzuki K, Nakanishi S (2006) Expression profile of BDNFresponsive genes during cerebellar granule cell development. Biochem Biophys Res Commun 341:304-309.

Schwartz PM, Borghesani PR, Levy RL, Pomeroy SL, Segal RA (1997) Abnormal cerebellar development and foliation in $\mathrm{BDNF}^{-1-}$ mice reveals a role for neurotrophins in CNS patterning. Neuron 19:269-281.

Sée V, Boutillier AL, Bito H, Loeffler JP (2001) Calcium/calmodulindependent protein kinase type IV (CaMKIV) inhibits apoptosis induced by potassium deprivation in cerebellar granule neurons. FASEB J 15:134-144.

Segal RA, Pomeroy SL, Stiles CD (1995) Axonal growth and fasciculation linked to differential expression of BDNF and NT3 receptors in developing cerebellar granule cells. J Neurosci 15:4970-4981.

Shieh PB, Hu SC, Bobb K, Timmusk T, Ghosh A (1998) Identification of a signaling pathway involved in calcium regulation of BDNF expression. Neuron 20:727-740.

Soha JM, Herrup K (1995) Stunted morphologies of cerebellar purkinje cells in lurcher and staggerer mice are cell intrinsic effects of the mutant genes. J Comp Neurol 357:65-75.

Tabuchi A, Sakaya H, Kisukeda T, Fushiki H, Tsuda M (2002) Involvement of an upstream stimulatory factor as well as cAMP-responsive-binding protein in the activation of brain derived neurotrophic factor gene promoter I. J Biol Chem 277:35920-35931.

Tao X, Finkbeiner S, Arnold DB, Shaywitz AJ, Greenberg ME (1998) $\mathrm{Ca}^{2+}$ influx regulates BDNF transcription by a CREB family transcription factor dependent mechanism. Neuron 20:709-726.

Tao X, West AE, Chen WG, Corfas G, Greenberg ME (2002) A calcium responsive transcription factor, $\mathrm{CaRF}$, that regulates neuronal activitydependent expression of BDNF. Neuron 33:383-395.

Timmusk T, Palm K, Metsis M, Reintam T, Paalme V, Saarma M, Persson H (1993) Multiple promoters direct tissue-specific expression of the rat BDNF gene. Neuron 10:474-489.

Vinet J, Carra S, Blom JM, Harvey M, Brunello N, Barden N, Tascedda F (2003) Cloning of a mouse $\mathrm{Ca}^{2+} / \mathrm{calmodulin}$-dependent protein kinase kinase beta $(\mathrm{CaMKK} \beta)$ and characterization of CaMKK $\beta$ and CaMKK $\alpha$ distribution in the adult mouse brain. Mol Brain Res 111:216-221.

Wayman GA, Lee YS, Tokumitsu H, Silva A, Soderling TR (2008) Calmodulinkinases: modulators of neuronal development and plasticity. Neuron 59:914-931. 
Wechsler-Reya RJ, Scott MP (1999) Control of neuronal precursor proliferation in the cerebellum by Sonic Hedgehog. Neuron 22:103-114.

Wei F, Qiu CS, Liauw J, Robinson DA, Ho N, Chatila T, Zhuo M (2002) Calcium calmodulin-dependent protein kinase IV is required for fear memory. Nat Neurosci 5:573-579.

West AE, Chen WG, Dalva MB, Dolmetsch RE, Kornhauser JM, Shaywitz AJ, Takasu MA, Tao X, Greenberg ME (2001) Calcium regulation of neuronal gene expression. Proc Natl Acad Sci U S A 98:11024-11031.

Wu GY, Deisseroth K, Tsien RW (2001) Activity-dependent CREB phosphorylation: convergence of a fast, sensitive calmodulin kinase pathway and a slow, less sensitive mitogen-activated protein kinase pathway. Proc Natl Acad Sci U S A 98:2808-2813.

Wu JY, Ribar TJ, Cummings DE, Burton KA, McKnight GS, Means AR (2000) Spermiogenesis and exchange of basic nuclear proteins are impaired in male germ cells lacking Camk4. Nat Genet $25: 448-452$.
Yamauchi J, Chan JR, Shooter EM (2003) Neurotrophin 3 activation of TrkC induces Schwann cell migration through the c-Jun N-terminal kinase pathway. Proc Natl Acad Sci U S A 100:14421-14426.

Zheng F, Soellner D, Nunez J, Wang H (2008) The basal level of intracellular calcium gates the activation of phosphoinositide 3-kinase-Akt signaling by brain-derived neurotrophic factor in cortical neurons. J Neurochem 106:1259-1274.

Zhou P, Porcionatto M, Pilapil M, Chen Y, Choi Y, Tolias KF, Bikoff JB, Hong EJ, Greenberg ME, Segal RA (2007) Polarized signaling endosomes coordinate BDNF-induced chemotaxis of cerebellar precursors. Neuron 55:53-68.

Zhu D, Wu X, Strauss KI, Lipsky RH, Qureshi Z, Terhakopian A, Novelli A, Banaudha K, Marini AM (2005) N-methyl-D-aspartate and TrkB receptors protect neurons against glutamate excitotoxicity through an extracellular signal-regulated kinase pathway. J Neurosci Res 80:104113. 